\title{
AN ELECTRON MICROSCOPIC OBSERVATION ON THE CYTOLOGICAL CHANGES IN THE EXPERIMENTAL DRUG-INDUCED LIPIDOSIS
}

\author{
YUKIO TASHIRO \\ Department of Pathology, School of Medicine, \\ Keio University, Tokyo, Japan
}

(Received for publication February 5, 1975)

\begin{abstract}
The fine structural changes induced by 4,4'-diethylaminoethoxy hexestrol dihydrochloride $(\mathrm{DH}) \rightarrow$ a coronary vasolidator-in the rat liver and pancreas were studied. The cytoplasmic change caused by the daily administration of $\mathrm{DH}$ was characterized by the appearance of numerous myeloid inclusion bodies. The myeloid bodies appeared at first near the Golgi complexes in the early stage of treatment and increased in number, and at the same time, the fusion of myeloid bodies occurred in proportion to the period of treatment. The myeloid bodies were tentatively classified into following four types: whorls of membrane (type I), dense bodies with a regular periodicity (45-55 $\AA$ ), such as finger-printed structure (type II), labyrinthine aggregates of smooth membrane and reticular internal structure surrounded by membranes (type III) and crystalline bodies showing an internal regular lattice pattern (type IV). There were also many intermediate types among them in the case of long term administration of DH. It is suggested that type III, IV myeloid bodies are formed through the stage of type I or type II myeloid bodies and that type I and type II myeloid bodies appear originally caused by DH administration. The myeloid bodies are assumed to be produced by the processes that the lipid metabolism is disturbed by DH itself and abnormal metabolites are formed and then, they are uptaken and accumulated in the lysosomes. After intralysosomal digestion, more resistant components of lipid remain and are condensed in the lysosomes. These residues, rich in phospholipids and free cholesterol are probably represented as myeloid structures. These cellular changes induced by $\mathrm{DH}$ administration were reversible in rats. The processes of cellular recovery and disappearance of myeloid bodies in rat liver and pancreas were also observed.
\end{abstract}

\section{INTRODUCTION}

Since the first report of Suga, et al. ${ }^{29}$ in 1965 on a case of "foam cell syndrome", which closely resembled the "sea-blue histiocytosis" described by Sawitsky ${ }^{20}$ and Silverstein, ${ }^{26,27}$ the increasing number of similar cases have been 
reported in Japan. This syndrome was characterized by the general fatigue and hyperlipemia of the patients and foamy swelling of peripheral leukocytes and bone marrow cells. This cellular changes were later proved, by means of electron microscope, to be due to the intracytoplasmic accumulation of numerous myeloid bodies in the cells concerned. The sudden increase of such cases in our country has led some investigators to suspect some medical drugs as the pathogenic agent. In 1969, Komiya, et al. ${ }^{18}$ pointed out, on the basis of clinical observation, the striking relationship between the occurrence of this syndrome and the use of a coronary vasodilator, 4,4'-diethylaminoethoxy hexestrol dihydrochloride (DH). On the other hand, Oda, et al.17 reported in 1969 the peculiar cases of "phospholipid fatty liver" which was characterized by the appearance of myeloid bodies in the liver of the patients with hepatosplenomegaly and hyperlipemia. These two syndromes were close resembled one to another in ultrastructural aspect and it was immediately proved that both the syndromes occurred after the administration of DH. Experimental induction of identical changes in rats by DH administration has been reported by several authors ${ }^{2,3,23,36}$ including us. ${ }^{30-34}$ According to these reports, the myeloid inclusion bodies were formed in the cells of various organs such as liver, kidney, pancreas, bone marrow, lung, heart, etc. The purpose of the present communication is to describe the details of the changes induced by $\mathrm{DH}$ in the rat liver and pancreas, in which the formation and disappearance of the myeloid bodies were more clearly investigated than in other organs.

\section{MATERIALS AND METHODS}

Male and female Wistar rats weighing $200-250 \mathrm{~g}$ were given daily with $\mathrm{DH}$ $(10 \mathrm{mg} / \mathrm{rat} / \mathrm{day})$ intraperitoneally or per os: intraperitoneal administration was applied for the short term administration up to 14 days, while oral administration using stomach-tube was applied for the long term one up to 100 days. Animals were divided into three experimental groups; Group 1. Animals were killed 8 and 12 hours, 1, 2, 3, 4, 5, 6, 7, 14, 30, 60 and 100 days after first administration. Group 2. Animals were killed 30,60 and 120 days after the termination of DH administration for 60 days. Group 3. Animals were killed 1, 2, 3, 4, 5, 6, 7 and 8 weeks after the termination of $\mathrm{DH}$ administration for 2 weeks. Group 3 experiment was carried out for the detailed observation on the recovery processes of cellular changes induced by DH. Liver and pancreas were examined by both light and electron microscopy. At least, two rats, both male and female, were used for each experiment comparing with control rats.

1) Light microscopic examination: Each tissue was fixed in $10 \%$ buffered 
formalin and/or Ciaccio's solution and the following stainings were carried out; Hematoxylin-eosin, Periodic acid Schiff staining, Mallory staining, Sudan Black $B$, Oil red $O$, Nile Blue and acid hematein staining. For light microscopic enzyme histochemical examination, tissues were fixed for 8-10 hours in Baker's $10 \%$ formol calcium $(\mathrm{pH}=7.1-7.2)$ and then sectioned by a Cryotome, and incubated in the substrates for acid phosphatase and $\beta$-glucuronidase activity for 30 minutes according to Barka-Anderson's method and Hayashi-Nakajima-Fishman's method.

2) Electron microscopic examination: Single fixation of materials with $1 \% \mathrm{OsO}_{4}(0.1 \mathrm{M} \text { phosphate buffered, } \mathrm{pH}=7.4)^{16}$ was performed for all experiments except for the case of electron microscopic cytochemical examination. The tissues were sliced and fxed in $1 \% \mathrm{OsO}_{4}$ for 2 hours and dehydrated in graded alcohol and embedded in epoxy resin according to Luft's method. ${ }^{14}$ After thin sectioning on LKB ultramicrotome and double staining with lead acetate and uranyl acetate, specimens were examined in a JEM-100B electron microscope. For the electron microscopic demonstration for acid phosphatase activity, specimens were fixed in $2.5 \%$ glutaraldehyde $(0.1 \mathrm{M}$ phosphate buffered, $\mathrm{pH}=7.4)$ for 30 minutes and incubated for 30 minutes in the Gomori's substrates. They were post-fixed in $1 \% \mathrm{OsO}_{4}$ and treated in the same way as mentioned above. For the morphological demonstration of free-cholesterol, Scharnbeck's ${ }^{22}$ and Williamson' $\mathrm{s}^{35}$ methods were used: Liver was fixed for two hours in $3 \%$ glutaraldehyde ( $0.1 \mathrm{M}$ cacodylate buffered, $\mathrm{pH}=7.4$ ) at the room temperature and incubated for 4 hours in the solution of saturated digitonin. After the postfixation with $1 \% \quad \mathrm{OsO}_{4}$ for 30 minutes, the specimens were treated in the same way as mentioned above.

3) Biochemical examination: Liver was perfused with cold saline solution and preserved in deep-freezer at $-20^{\circ} \mathrm{C}$. The crude lipids were extraced in Folch's solution ${ }^{10}$ from $1 \mathrm{~g}$ of the liver and re-extracted for purification in $1 \mathrm{ml}$ of Folch's solution after evaporation at $60^{\circ} \mathrm{C}$. For the quantitative analysis of lipids, the methods of forigil column chromatography ${ }^{5}$ and thin-layer chromatography (TLC) using Silica gel G were examined.

4) Isolation of myeloid bodies from the rat liver: An attempt to isolate the specific myeloid inclusion bodies from the rat liver induced by 60 days administration of $\mathrm{DH}$ was carried out. The modified method of Kamoshita's ${ }^{12}$ and Samuel's ${ }^{21}$ using the discontinuous sucrose density gradient (Table 1) was performed. 
Table 1

ISOLATIOH OF LANELLAR INCLUSION BODIES IN TME RAT LIVER AFTER DH ADMINISTRATION

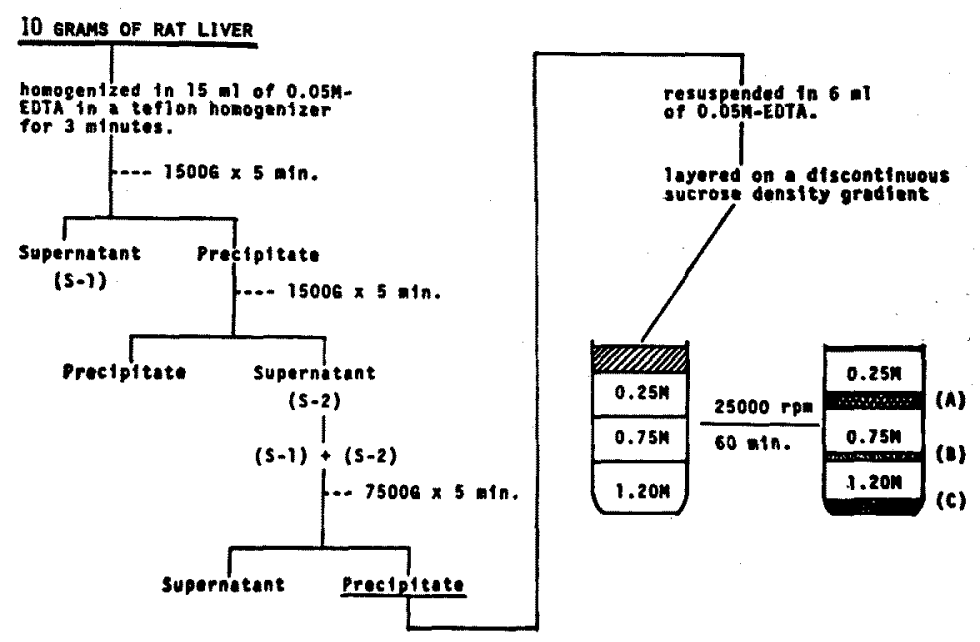

RESULTS

Light microscopic studies:

No distinct changes in the rat liver and pancreas were seen in the cases of the short term administration of DH. Foamy swelling of cells were found in the cases of long term administration of $\mathrm{DH}$. The change was more prominent in Kupffer's cells, epithelial cells of intrahepatic bile ducts and of pancreatic ducts than in the hepatocytes and pancreatic acinar cells. The cytoplasmic vacuolization as seen in the fatty metamorphosis was not recognized. Except for the foamy swelling, the histological changes were minimal. Neither fibrotic change nor inflammatory change was detected in the liver and pancreas. Lipid staining including Oil red $O$, Sudan black $B$, Nile blue and acid hematein showed numerous fine lipid droplets in the cytoplasms of hepatocytes, Kupffer's cells, epithelial cells of bile ducts and acinar cells and duct epithelia of the pancreas. Periodic acid Schiff staining and Alcian blue staining for mucopolysaccharide were negative in the foamy swelling cells. Other histochemical examination showed no significant changes, but lysosomal enzyme activities for acid phosphatase and $\beta$-glucuronidase showed an obvious increase in the foamy swelling cells as compared with the control ones. The results of histochemical examination at light microscopic level are summarized in Table 2. 
Table 2

Histochemical analysis of cytoplasmic bodies

\begin{tabular}{ll}
\hline \hline SUDAN BLACK B & BLACK \\
ACID HEMATEIN & BLUE-BLACK \\
OIL RED O & SLIGHTLY POSITIVE \\
NILE BLUE & METACHROMASIA, SLIGHT \\
PAS STAIN & NEGATIVE \\
ALCIAN BLUE STAIN & NEGATIVE \\
ACID PHOSPHATASE ACTIVITY & $\uparrow \quad \uparrow$ \\
$\beta$-GLUCURONIDASE ACTIVITY & $\uparrow$ \\
\hline
\end{tabular}

Electron microscopic studies:

I) Morphology of the myeloid bodies.

The characteristic change induced by $\mathrm{DH}$ administration was the formation of numerous myeloid inclusion bodies in the cytoplasm of various cells. The myeloid bodies were the spherical or irregularly shaped dense granules of varying diameter, ranging from 0.5 to $2 \mu$. They were bounded by a distinct limiting membrane and contained fine granular matrix and characteristic myelin-like internal structure within. The myelin-like internal structures showed noticeable differences in appearance from one to another. They were arbitrarily classified into the following four types according to their internal structures (Schema 1). The type I myeloid bodies showed a whorl-like internal structure composed of concentrically arranged membranes of various thickness (Fig. 1). The type II myeloid bodies were dense compact granules showing concentric lamellar internal structure with a regular periodicity of 45-55 \& (Fig. 2). The type III myeloid bodies had a reticular or labyrinthine internal structure (Fig. 3) and the type IV showed a characteristic lattice-work (Fig. 4). The appearance of the four types of myeloid inclusion bodies are diagrammatically represented in Schema 1. The limiting membrane of myeloid bodies was usually distinct, but in only exceptional cases of myeloid bodies containing type III and IV internal structure, it was lacking. In such cases a direct communication between the membranous internal structure of myeloid bodies and the endoplasmic reticulum was occasionally seen (Fig. 5). The various intermediate forms between these four types of myeloid bodies were found. They were the ones of type I-III, type II-III and type II-IV as shown in Fig. 4 and 6. This classification of myeloid inclusion bodies induced by $\mathrm{DH}$ administration was largely based upon the classification of myeloid bodies made by Chen and Yates ${ }^{6}$ on the triparnol-treated rat adrenals. There was a narrow space, named as a matrix of the myeloid body in this study, which contained amorphous and fine granular materials between the limiting 
membrane and the myelin-like internal structure and in the central core of the myelin-like structure.

\section{II) Findings of the liver.}

Numerous myeloid bodies in almost all the cell components in the liver, including hepatocytes, Kupffer cells, endothelial cells of sinusoids and interstitial blood vesseles, epithelial cells of bile ducts and interstitial cells of periportal triads. In hepatocytes, the myloid bodies had been found, though in small numbers, as early as 8 hours after initial administration of DH and they were increasing in number in proportion to the duration of the $\mathrm{DH}$ administration up to about two weeks (Fig. 7 9). In this stage, the majority of the myeloid bodies were of Type I and a small number of Type II. After two weeks, no more appreciable increase in the number of myeloid bodies was noticed, but they began to show the variation in their internal structure. In this stage, type III and IV myeloid bodies appeared and gradually increased in number and finally in the case of long term administration, the majority of myeloid bodies were those of type III or IV (Fig. 10, 11). Type I and type II myeloid bodies were only occasionally encountered in this stage. Small numbers of type III and type IV myeloid bodies lacking the limiting membrane were detected. In contrast to the hepatocytes, all the cell components in the liver except for hepatocyte showed only type I myeloid bodies throughout the experiment and the other types of myeloid bodies were only occasionally encountered in these cells, especially in Kupffer's cells and epithelial cells of bile ducts (Fig. 12).

a) Formation of the myeloid bodies.

As noted above, the myeloid bodies and their precursors were already found in small numbers as early as 8 hours after initial $\mathrm{DH}$ administration and they gradually increased in number up to about 2 weeks (Fig. 7). The precursor of the myeloid body was a membrane-bounded dense body containing fine granular and filamentous structure (Fig. 7). They were at first located predominantly in the vicinity or the periphery of the Golgi region (Fig. 7, 8). And there, the smooth-surfaced endoplasmic reticulum, Golgi vesicles and Golgi saccules seemed to have increased and slightly dilated. A small number of precursors of the myeloid bodies were detected in the Golgi areas and showed a close association with the Golgi elements and smooth-surfaced endoplasmic reticulum. In larger myeloid bodies, the internal whorl-like structure became distinct and there were also those containing several whorls indicating that fusion of smaller bodies had occurred. With the continuation of $\mathrm{DH}$ administration, the number of myeloid bodies increased up to about 2 or 3 weeks and then no appreciable increase in number of myeloid bodies was noticed. The majority of myeloid bodies in the 
early stage up to about 2 weeks were the type I and a small number of the type II bodies (Fig. 9). After becoming plateau in number, type III, type IV and their intermediate type ones increased and finally, greater parts of the cytoplasms in the long term administration were occupied by numerous myeloid bodies showing various internal structures (Fig. 10, 11).

\section{b) Disappearance of the myeloid bodies.}

For detailed observation of decrease and disappearance of the myeloid bodies: from the hepatocytes, Group 3 experiment was carried out. The hepatocytes were occupied with numerous type I and a small number of type II myeloid bodies. at 2 weeks after the initial administration of $\mathrm{DH}$ and other types of myeloid bodies could not be found at that time. One or two weeks after the termination of $\mathrm{DH}$ administration for 2 weeks, myeloid bodies began to decrease in number and their electron density increased slightly. At the same time the type I myeloid bodies decreased in number and the type III and IV myeloid bodies began to appear (Fig. 13). And then, various types of myeloid bodies began to be found in the hepatocytes as seen in the case of long term administration such as 100 day's administration. At the same time, the density of the myeloid bodies increased and their internal structures, such as whorls of membrane, reticular pattern and lattice pattern became obscure (Fig. 13). And then the density, size and number of the myeloid bodies gradually decreased. Finally various internal structures of the myeloid bodies disappeared completely 8 weeks after the termination of daily $\mathrm{DH}$ administration for 2 weeks and in place of them a few peribiliary dense bodies and autophagic vacuoles were detected (Fig. 14). In Group 2, in which the DH administration was terminated after 60 day treatment, the disappearance of myeloid bodies occurred 4 months after the termination of $\mathrm{DH}$. The finding suggesting that the myeloid bodies were excreted directly from hepatocytes into the bile canalicules could not be seen in this study. On the other hand, the findings suggesting that the numerous myeloid bodies which occupied the whole cytoplasm scattered into the lumen of bile ducts through rupture of cell membranes of bile duct epithelials and cellular destruction were also observed (Fig. 12).

c) Light and electron microscopic histochemistry.

The activities of acid phosphatase and $\beta$-glucuronidase in light microscopic histochemical examination markedly increased as compared with control groups (Fig. 15). Large numbers of fine granular reactive products for acid phosphatase and $\beta$-glucuronidase deposited in the hepatocytes, Kupffer's cells and epithelial cells of bile ducts were seen. The reaction products for acid phosphatase were more strongly deposited than those for $\beta$-glucuronidase. In electron microscopic 
cytochemical examination, reaction products for acid phosphatase were detected in the matrix and central core of the myeloid bodies, but were lacking in the membranous arrays of the myelin-like structures (Fig. 16). The reaction products could be detected in the type I myeloid bodies more easily than in other ones. "Digitonin-method" reported by Williamson and Scharnbeck, et al. was used for morphological demonstration of the increase of free cholesterol in the rat liver. Digitonin-cholesterol complexes were recognized as darkly stained needles or spicules. On cross section, they presented as dark circles or spiral-like lamellar structures around a slightly stained central core. Spirals consisted of 1/1/2 turns. The diameter of such cross sections was 70-100 nm. Longitudinal sections showed them to be spindle shaped. They were up to $1 \mu$ in length (Fig. 17,18 ). The distribution of digitonin-cholesterol complexes in the cells was irregular, but they were more frequently seen near cell surface, either within the cytoplasm or in the space of Disse. They were also found in the matrix of the myeloid bodies as the reaction products for acid phosphatase. Many of the complexes were aggregated in the matrix of the myeloid bodies and occupied almost whole spaces of the matrix. The lamellar structures of complexes seemed partially to transcient to the lamellar and membranous internal structures of the myeloid body (Fig. 17, 18).

\section{d) Biochemical examination.}

The results of biochemical examination about the lipids extracted from the rat liver are summarized in Table 3 . With the continuation of $\mathrm{DH}$ administration, the contents of phospholipids and free-cholesterol increased remarkably. But the contents of other lipids showed no remarkable changes as compared with control cases. After the termination of $\mathrm{DH}$, the contents of phospholipid and free-cholesterol decreased gradually, and finally, returned to the control level as shown in Table 3.

\section{III) Findings of the pancreas.}

The main alteration in pancreatic acinar cells was also the formation of myeloid bodies. A small number of the myeloid bodies appeared 8 hours after administration of $\mathrm{DH}$ in the supranuclear region, i.e., near the Golgi complexes. They became soon more complex and larger in proportion to the periods of administration (Fig. 19, 20). Other detailed cellular changes induced by $\mathrm{DH}$ were almost the same noted above in the liver. Throughout the course of $\mathrm{DH}$ administration, the type II and their complex myeloid bodies predominated in the pancreatic acinar cells. And some of the largest complex myeloid bodies reached the size of nucleus or more (Fig. 21). But in the pancreatic duct epithelia and islet cells, the type I myeloid bodies and their complex forms occupied the whole 
Table 3

Changes of lipid contents after $D H$ administration in the rat liver

\begin{tabular}{|c|c|c|c|c|c|c|c|}
\hline & $\begin{array}{l}\text { Total } \\
\text { Lipid }\end{array}$ & $\begin{array}{l}\text { Phospho } \\
\text { Lipid }\end{array}$ & $\begin{array}{l}\text { Free } \\
\text { Chole- } \\
\text { sterol }\end{array}$ & $\begin{array}{l}\text { Chole- } \\
\text { steool } \\
\text { Ester }\end{array}$ & $\begin{array}{l}\text { Trigly- } \\
\text { ceride }\end{array}$ & $\begin{array}{l}\text { Digly- } \\
\text { ceride }\end{array}$ & $\begin{array}{l}\text { Mono- } \\
\text { glyceride }\end{array}$ \\
\hline & $\begin{array}{l}\mathrm{mg} / \mathrm{g} \\
\text { liver }\end{array}$ & $\begin{array}{l}\text { Lecithine } \\
\mathrm{mg} / \mathrm{g} \\
\text { liver }\end{array}$ & $\begin{array}{l}\text { Chole- } \\
\text { sterol } \\
\mathrm{mg} / \mathrm{g} \\
\text { liver }\end{array}$ & $\begin{array}{l}\text { Glycerol } \\
\mathrm{mg} / \mathrm{g} \\
\text { liver }\end{array}$ & $\begin{array}{l}\text { Glycerol } \\
\text { mg/g } \\
\text { liver }\end{array}$ & $\begin{array}{c}\text { Glycerol } \\
\text { mg/g } \\
\text { liver }\end{array}$ & $\begin{array}{l}\text { Glycerol } \\
\text { mg/g } \\
\text { liver }\end{array}$ \\
\hline 10 days & 48.2 & 33.2 & 4.69 & 0.21 & 0.02 & 0.10 & 0.06 \\
\hline 20 days & 48.0 & 35.0 & 4.85 & 0.23 & 0.02 & 0.23 & 0.09 \\
\hline days & 59.8 & 38.8 & 6.16 & 0.23 & 0.02 & 0.14 & 0.12 \\
\hline days & 68.6 & 39.5 & 6.42 & 0.63 & 0.04 & 0.18 & 0.14 \\
\hline 100 days & 66.5 & 47.7 & 8.29 & 0.29 & 0.02 & 0.24 & 0.13 \\
\hline $60-60$ days & 34.2 & 28.0 & 3.85 & 0.18 & 0.11 & 0.14 & 0.14 \\
\hline Control & 43.9 & 24.6 & 3.45 & 0.19 & 0.58 & 0.45 & 0.26 \\
\hline
\end{tabular}

cytoplasm. Focal degradation was rare, but present occasionally in the cases of long term administration. Other cellular changes in pancreas induced by $\mathrm{DH}$ were almost undetectable. After the termination of $\mathrm{DH}$ administration, the myeloid bodies decreased in number and their internal structure became gradually obscure, and they became to amorphous dense bodies finally. In addition to the intracellular digestion, discharge of the contents of the myeloid bodies which had reached the apical portion of the cells into the extracellular space occurred in a number of cases, presumably by exocytosis as for zymogenic secretion granules, and these exocytotic figures were never observed in the liver (Fig. 22, 23). The complex myeloid bodies reached to the apical portion of the acinar cells gradually with the duration of DH administration. There were large vacuoles in which myeloid bodies were contained irregularly. In the lumen of the pancreatic duct, the scattered myeloid bodies could be detected, which seemed to have been just exocytosed (Fig. 22). The same phenomenon was observed in the epithelial cells of pancreatic ducts (Fig. 23). In this point of view of the disappearance processes, there was a difference between pancreas and liver.

\section{DISCUSSION}

The characteristic changes induced in the rat by administration of 4,4'diethylaminoethoxy hexestrol dihydrochloride $(\mathrm{DH})$ are the formation of intracytoplasmic myeloid bodies. Our preliminary observation revealed that the similar myeloid body formation was found in a wide variety of cells in almost all tissues. sofar examined, including the myocardium, lung, blood vessels, small intestine, 
liver, pancreas, kidney, bone marrow, and peripheral blood cells. Only one exception was the central nervous tissues, in which only a trace of myelin-like bodies were found in both nerve and glial cells. In the present study the author described the changes in the liver and pancreas in detail, because in these organs the process of formation and disappearance of myeloid bodies were well recognizable.

\section{a) Histochemical and biochemical composition of myeloid bodies.}

The histochemical data indicate that the myeloid bodies are rich in phospholipids (Table 2), and also biochemical data of lipid analysis show that the myeloid bodies are rich in phospholipid and free-cholesterol (Table 3). Yamamoto, et al. ${ }^{36}$ reported from their detailed lipid analysis that the increased phospholipids consisted of phosphatidyl inositol, phosphatidyl choline and lyso-bis phosphatidic acid that were acidic phospholipids. And also Table 3 indicates that phospholipids and free-cholesterol increased gradually in proportion to the length of $\mathrm{DH}$ administration. The amounts of lipid contents in biochemical analysis and the number of myeloid bodies in electron microscopic observation are well paralleled; when the myeloid bodies disappeared perfectly the lipid contents recovered to the control level. From this fact, it seems that abnormally increased lipids induced by $\mathrm{DH}$ administration are accumulated or packed into the myeloid bodies. The matrix of the myeloid bodies shows a positive acid phosphatase reaction (Fig. 16), however the arrays of membranes failed to show a positive acid phosphatase reaction. It is reasonable to assume that the myeloid bodies are of lysosomal in nature, and that after a certain degree of intralysosomal digestion, more resistant components of lipids may remain as residue and represent the myeloid structure.

According to Williamson's $s^{35}$ and Scharnbeck's ${ }^{22}$ methods, the complexes of free-cholesterol and digitonin, "digitonides", are detected in the matrix of the myeloid bodies (Fig. 17, 18). From this fact, abnormally increased free cholesterol are also accumulated in the matrix of myeloid bodies. On the other hand, the internal lamellar structures of the myeloid bodies display a periodicity of approximately $45-55 \AA$ in this study. This fact shows that the lamellar structure of the myeloid bodies is thought to be composed of lipids, mainly phospholipids, as Stoeckenius ${ }^{28}$ described. Furthermore we succeeded in purification of myeloid bodies isolated from rat liver according to the modified methods of Samuel's ${ }^{21}$ and Kamoshita's ${ }^{12}$ (Fig. 24). Aketa, et al. ${ }^{2}$ also succeeded in isolation of myeloid bodies using another method and reported that abnormally increased lipids are contained in the purified myeloid bodies and at the same time, DH itself is contained in them. Detailed lipid analysis of the purified myeloid bodies in this study was not yet carried out. At the same time, more refined techniques for the 
isolation of these myeloid bodies are being undertaken and consequently, definitive conclusion on their chemical nature awaits the results of these experiments.

\section{b) Formation and origin of the myeloid bodies.}

There is no differences in the process of formation of myeloid bodies between hepatocytes and pancreatic acinar cells. There is a morphological evidence to support the view that the myeloid bodies are derived from the Golgi complexes. In the early stage of $\mathrm{DH}$ administration, the myeloid body is small in size, but has a distinct limiting membrane and matrix. At the same time, a small number of myeloid bodies are elongated in shape and have a certain resemblance to the Golgi saccules. Furthermore, there are same changes near the Golgi complexes even in the later stages, in which numerous myeloid bodies have already appeared in the cytoplasm. This fact seems to indicate that the myeloid bodies are being produced through the Golgi complexes during the DH administration. From this study, the myeloid bodies induced by $\mathrm{DH}$ administration are thought to be formed through these four steps which can be followed in Fig. 7 and 8; (1) Golgi vessicles increase in number and Golgi saccules dilate. (2) Fine granular and amorphous materials with high electron density accumulate in the dilated saccules. (3) Concentric or parallel membrane begin to be formed within these dilated saccules. (4) These myeloid bodies fused to form larger complex bodies and increase in number.

The fact that the positive reaction for acid phosphatase is demonstrated in the matrix of the myeloid bodies as well as in the small space of central core of lamellar structures indicates that the myeloid bodies are lysosomal in nature. This reveals a strong support for the morphological evidence just described above, that myeloid bodies originate from the Golgi complex, because the primary lysosomes are produced through the Golgi complex or GERL system described by Novikoff. ${ }^{38}$ As shown in our previous report, ${ }^{33}$ the myeloid bodies are detected in the granules of neutrophilic and eosinophilic leukocytes which are typical primary lysosomes and are formed in the Golgi complex. This may indicate the Golgi-origin of myeloid bodies in a variety of cell types, i.e. primary lysosomes, while Yates ${ }^{37}$ and Hruban ${ }^{11}$ interpreted in a broad sense that the myeloid bodies were secondary lysosomes in nature.

The electron microscopic figures in this drug-induced experimental lipidoses by $\mathrm{DH}$ administration beared a close resemblance to those of congenital lipidosis such as Niemann-Pick disease, Tay-Sachs disease etc. It is widely accepted that these congenital lipidoses are formed by the deficiency of "lytic enzyme", responsible for the reduction of synthesized lipids and that they are a kind of lysosomal diseases. In the same way, abnormally formed lipids by $\mathrm{DH}$ administration are 
accumulated and packaged into the lysosomes and gradually received intralysosomal digestion. After a certain degree of intralysosomal digestion, the residues are accumulated and packaged into the lysosomes, and consequently become to show such myeloid structures. It is proved by Akeda ${ }^{3}$ and Yamamoto ${ }^{36}$ that DH itself was detected in the cytoplasm. From these facts, the drug-induced lipidosis by $\mathrm{DH}$ is thought to be produced through the insufficient digestive activity of lysosomal enzymes. Factors which cause such a lysosomal insufficiency may be variable. However, the following two possibilities should be considered as the major mechanisms. The one is that the enzymes which normally digest the the phospholipid are inhibited in activity by DH and the other is that DH enhances the production of abnormal phospholipids to such an extent that they are difficult to be digested by preexisting lysosomal enzymes. In the present state of our investigation, it is difficult to decide which of these two mechanisms is responsible to the phospholipidosis induced by $\mathrm{DH}$. However the second mechanism seems to be more probable than the first, because type III and IV myeloid bodies, which are thought to be formed from type I and/or II myeloid bodies by the "lytic" action of lysosomal enzymes, do also appear in long term cases, in which $\mathrm{DH}$ is continuously administered.

As mentioned above, the internal structures of myeloid bodies were divided into four types. There appeared type $I$ and a small number of type II myeloid bodies in the hepatocytes in the case of relatively early stage of administration, but in the case of long term or after the termination of administration, the type III and IV myeloid bodies appeared. Whilst the type III and IV myeloid bodies do not yet appear in hepatocytes at second week of DH administration, they soon begin to appear after the termination of DH. And also it is reasonable to assume that type III and IV myeloid bodies are derived from type I or type II bodies. These facts in this study are in contrary to the experimental results carried out. by Yates, et al. ${ }^{37}$ in adrenal cortical cells using triparanol, in which they concluded that type III myeloid body was primarily produced and other myeloid bodies were derived through the stage of type III bodies. Although the mechanism is not clear how to provoke such an alteration of the internal structures of myeloid bodies, it is assumed that they are derived from the results of digestion-process of myeline structures. On the other hand, the type III and IV myeloid bodies can be considered as gatherings of tubular and membranous structures. Sometimes they are lacking in the limiting membrane, and furthermore, membranous elements of the internal structures of them show a part of direct transition to membranes of the endoplasmic reticulum. It is undeniable from the facts noted above that phospholipids of the myeloid bodies may be reutilized for a new production of membranes. Stoeckenius ${ }^{28}$ mentioned that changes in temperature and 
in the contents of water might alter the phospholipids from lamellar to the hexagonal phase. But the tissues in this study were always prepared in ice-cold fixative and temperature during dehydration was kept rather constant, and so it is ruled out that the alteration of the internal structures is due to the artifacts in the process of specimen-preparation. It is possible that the differences of internal structures of the myeloid bodies may be caused by the direction and inclination of sections. To confirm this possibility, tilting-method of the pathway of electron beam was used. And when the plane of section of the myeloid bodies is tilted with respect to the pathway of the electron beam, the internal structures of myeloid bodies do not change from one pattern to another, that is, from reticular to crystlline. From this fact, the alteration of internal structures are also not due to the direction and inclination of sections.

c) Disappearance of the myeloid bodies.

In the hepatocytes in the cases of the long term administration or after the termination of $\mathrm{DH}$ administration, autophagic vacuoles or small dense bodies including fragments of myeline structures, which are said to be lysosome, sometimes appeared in addition to the typical myeloid bodies. There often appeared materials seemed to be small fat droplets in these dense bodies. These findings thought to show the processes that the myeline-like structures in the myeloid bodies are gradually digested and resolved. The figures are detected that myeloid bodies are exocytosed from the pancreatic acinar and centroacinar cells. Furthermore, there are swelling and balooning cells which are filled up with numerous myeloid bodies such as epithelial cells of bile duct or pancreatic duct and Kupffer's cells. It is possible in such cells that myeloid bodies are eliminated from the cytoplasm through the rupture. As mentioned above, there are various ways in the processes of disappearance of the myeloid bodies; they are the mechanisms of digestion, resolution, exocytotic phenomena by reversed pinocytosis and elimination by cellular destruction.

d) Pathogenesis induced by DH administration.

4,4'-diethylaminoethoxy hexestrol dihydrochloride (DH) is a kind of coronary vasodilators exploited in Italy and consists of two different radicals, diethylaminoethanol and hexestrol as shown below.

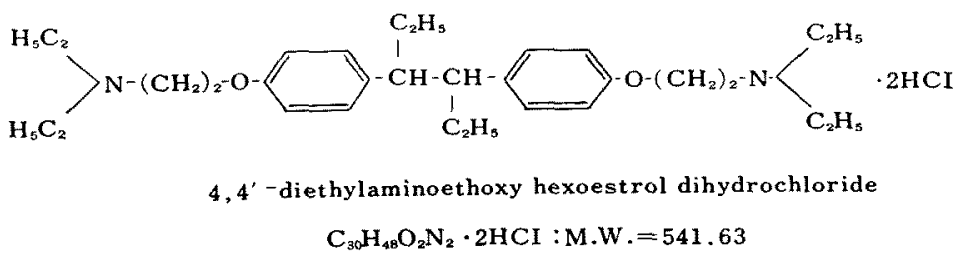


Triparanol, ${ }^{6,7,11,23}$ chloroquine, ${ }^{8,9}$ chlorophentamine ${ }^{15}$ and the others $\mathrm{s}^{13,19}$ have been said to be the drugs that induce the same various intracytoplasmic myeloid bodies. It is interesting that triparanol (MER-29) has the same radical of diethylaminoethanol as $\mathrm{DH}$, but chlorophentamine dose not. And there is no necessity for the radical of diethylaminoethanol to disturb the lipid metabolism, but the complexes of diethylaminoethanol and other radicals may disturb it. Furthermore, myeloid bodies were not produced by the individual administration of diethylaminoethanol and hexestrol from the result of Kanetaka's ${ }^{13}$ experiment.

Triparanol ${ }^{7,11}$ is known to alter cell metabolism in three ways: (1) it produces certain toxic responses, (2) it blocks cholesterol synthesis, and (3) it produces an accumulation of the intermediate, desmosterol. Phillips ${ }^{19}$ and Akeda ${ }^{1,2}$ reported that desmosterol also increased in the rat liver treated with $\mathrm{DH}$. It seems that $\mathrm{DH}$ may have at least same pharmacologic action as triparanol, but other detailed mechanism has been yet obscure. Akeda, et al. ${ }^{3}$ also showed that myeloid bodies appeared in the cytoplasm of the cultured Hela-cells and cultured fetal hepatic cells which were incubated in the medium mixed with the solution of DH. From these evidence, DH may alter the cellular metabolism in the ways described below; (1) it is absorbed directly through cell membrane into the cytoplasm, (2) it blocks or disturbs a kind of enzyme-system in the process of lipid metabolism and alters normal process of lipid metabolism, and then (3) abnormally increased or newly produced lipids are accumulated into the lysosomes. It is distinct that the cellular changes induced by $\mathrm{DH}$ are reversible in this study, not only from morphological observation, but also from the data of lipid analysis. Yamamoto, et al. ${ }^{36}$ also reported from their biochemical lipid analysis that the changes were reversible, but that the recovery processes are different between the species of experimental animals. On the other hand, Shikata, et al. ${ }^{24,25}$ reported in the human autopsy cases taking $\mathrm{DH}$ for a long term that cellular changes in the liver are progressive and finally develop into 'liver cirrhosis', named "phospholipid fatty liver cirrhosis". But in these experimental cases administrating $\mathrm{DH}$ for a long term, no cases which developed into 'liver cirrhosis' were observed. This may be because of the difference between species as Yamamoto, et al. $^{36}$ mentioned.

Lastly, it is concluded from the observation of this study that myeloid bodies disappear in three ways: (1) they receive intracellular digestion, (2) they are excreted through exocytotic process, reversed pinocytosis, without intracellular digestion, and (3) they are released by the cellular collapse.

The results of the observation mentioned above in this study are summarized in the Schema 2. 


\section{SUMMARY}

4,4'-diethylaminoethoxy hexestrol dihydrochloride (DH) - a coronary vasodilator-is known to cause an extensive phospholipid accumulation in a variety of cells of human and rat. In this report, the fine structural changes induced by this drug in the rat liver and pancreas were studied. The cytoplasmic change caused by the daily administration of $\mathrm{DH}$ was characterized by the appearance of numerous myeloid inclusion bodies. The myeloid bodies were membrane-limited spherical or irregularly shaped bodies ranging from $0.5 \mu$ to $2 \mu$ in diameter. Characteristic myelin-like or lattice-like internal structures were present within them. The internal structures occupied the major part of each myeloid inclusion. bodies and the remaining narrow spaces were filled with the matrix consisting. of fine granular materials. Positive acid phosphatase activity was demonstrated in the matrix, indicating that the myeloid bodies were lysosomal in nature. Free: cholesterol was also demonstrated histochemically in the matrix of myeloid bodies. The appearance of internal structures of myeloid bodies showed wide variation and they were tentatively classified into following four types: those with internal structure composed of whorls of laminated membranes (type I), those with dense internal structure showing finger print-like concentric lamellar with a regular periodicity (45-55 $\AA$ ) (type II), those with labyrinthine aggregates of smooth membranes (type III) and those with lattice-like internal structure (type IV). Many intermediate forms were present among these four types. In the initial stage of $\mathrm{DH}$ administration myeloid bodies appeared at first near the Golgi complexes and the transition from Golgi saccules to myeloid bodies was demonstrated. In the following stages myeloid bodies gradually increased in number and they fused to each other to form larger bodies. In this stage only type I and II myeloid bodies were discernible. In hepatocytes type I distinctly predominated over type II, whilst the latter largely exceeded the former in number in pancreatic acinar cells. In the later stages of $\mathrm{DH}$ treatment, type III and IV appeared and increased in number until these two types exceeded the type I and II in number. After the discontinuation of $\mathrm{DH}$ administration, the myeloid bodies decreased in number and disappeared almost completely about 2 months after the discontinuation. In cases, in which the administration of $\mathrm{DH}$ was stopped in relatively early steres when type III and IV myeloid bodies were not yet found, type I and II gradually replaced by type III and IV myeloid bodies, as the number of total myeloid bodies. decreased. It is concluded from these findings that type III and IV myeloid bodies are transformed from type I and II. Biochemical analysis of liver tissues showed the close parallelism between the amount of phospholipid and the number of myeloid bodies. This result indicates that the phospholipid is accumulated within the myeloid bodies. As the possible mechanism of myeloid body formation, 
the insufficient lysosomal digestion of abnormal metabolites resulted from disturbance of lipid metabolism induced by $\mathrm{DH}$ administration. Although the process of formation of myeloid bodies was identical in both hepatocytes and pancreatic acinar cells, the fate of myeloid bodies in cases of the long term administration or after the termination of $\mathrm{DH}$ administration was different in both cell types. These differences in the mechanisms of disappearance of myeloid bodies, such as digestion, resolution, exocytosis and elimination by cellular destruction might be caused by the differences of lysosomal activities or lipid metabolisms in both cell types.

\section{ACKNOWLEDGEMENT}

The author wishes to thank Dr. Tadayoshi Kobayashi, Professor of Pathology, Tokai University, School of Medicine, Dr. Keizo Kageyama, Professor of Pathology, Keio University School of Medicine, and Yonosuke Watanabe, Associate Professor of Pathology, Keio University School of Medicine, for their valuable advice, and also wishes to thank Dr. Tsuyoshi Kanno for his co-operation in chemical analysis of lipid and Mr. Yasuhiro Enomoto for his technical assistance.

\section{REFERENCES}

1. Adachi, S., Yamamoto, A., Shinji, Y., Nasu, T., Seki, K. and Nishikawa, M.: Studies on drug induced lipidosis (1) Reports of clinical cases. J. Jap. Soc. Intern. Med. 60: 34-44, 1971

2. Akeda, S., Kawai, K., Tsujimura, R., Kosaka, Y. and Takeda, S.: Biochemical properties of myeloid inclusion bodies isolated from rat river treated by 4,4'diethylaminoethoxy hexestrol dihydrochloride. IGAKU NO AYUMI 83: 30-31, 1972 (Jap.)

3. Akeda, S., Kawai, K., Tsujimura, R. and Takeda, S.: Pathobiochemistry of druginduced phospholipidosis. Tr. Soc. Path. Jap. 61: 81, 1972 (Jap.)

4. Barka, T. and Anderson, P. J.: Histochemical methods for acid phosphatase using hexazorium pararosaline as complex. J. Histochem. Cytochem. 10: 741, 1962

5. Carrol, K. K.: Separation of lipid classes by chromatography on florisil. J. Lipid Res. 2: 135-141, 1961

6. Chen, I-LI and Yates, R. D.: An ultrastructural studies of opaque cytoplasmic inclusions induced by triparanol treatment. Amer. J. Anat. 121: 705-726, 1967

7. Diert, S. E. and Scallen, T. J.: An ultrastructural and biochemical studies of the effects of three inhibitors of cholesterol biosynthesis upon murine adrenal gland and testis. Histochemical evidence for a lysosome response. J. Cell Biol. 40: 44-60, 1969

8. Fedorko, M. E.: Effect of chloroquine on morphology of leukocytes and pancreatic exocrine cells from the rat. Lab. Invest. 18: 27-37, 1968

9. Fedorko, M. E.: Effect of chloroquine on morphology of cytoplasmic granules in maturing human leukocytes-an ultrastructural study. J. Clinic. Invest. 46: 19321942,1967

10. Folch, J. and Lees, M.: A simple method for the isolation and purification of total lipids from animal tissues. J. Biol. Chem. 226: 497-509, 1957 
11. Hruban, Z., Swift, H. and Slesers, S.: Effect of triparanol and diethanolamine on the fine structure of hepatocytes and pancreatic acinar cells. Lab. Invest. 14: $1652-1672,1965$

12. Kamoshita, S., Aron, A. M. and Suzuki, K.: Infantile Niemann-Pick Disease-a chemical study with isolation and characterization of membranous cytoplasmic bodies and myeline. Amer. J. Dis. Child. 117: 379-394, 1969

13. Kanetaka, T.: An experiment about the appearance of myeloid bodies between the drugs with radicals of diethylaminoethanol and hexestrol. The syposium for the 2nd. drug induced hepatic disorders. 133-140, 1972 (Jap.)

14. Luft, J. H.: Improvements in epoxy resin embedding methods. J. Biophysic. Cytol. 9: $409-414,1961$

15. Lüllmann, R., Iüllmann-Rauch and Reil, G-H.: A comparative ultrastructural study of the effects of chlorphentermine and triparanol in rat lung and adrenal gland. Virchows Arch. Abt. B Zellpath. 12: 91-103, 1973

16. Milloning, G.: Advantage of a phosphate buffer for $\mathrm{OsO}_{4}$ solution fixation. J. Appl. Phys. 32: 1937, 1961

17. Oda, T., Shikata, T., Naito, C., Suzuki, H., Kanetaka, T., Iino, S., Miyake, K., Sakai, T., Onoda, H., Fujiwara, K., Yamanaka, M., Shimizu, N. and Yoshitoshi, Y.: Phospholipid fatty liver: a report of three cases with a new types of fatty liver. Jap. J. Exp. Med. 40: 127-140, 1970

18. Onozawa, Y., Adachi, Y., Furusawa, S., Hiezawa, K., Tsuchiya, S., Sakamoto, Y., Mitsunaga, K. and Komiya, M.: Clinicopathological studies on the so-called foam cell syndrome associated with a long-term use of a coronary dilating agent. J. Jap. Societ. Intern. Med., 59: 1229-1234, 1970 (Jap.)

19. Phillips, W. A. and Arigan, J.: Inhibition of cholesterol biosynthesis in the rat by 3 $\beta$-(2-diethylaminoethoxy) androst-5-en-17-noe hydrochloride. Proc. Soc. Exp. Biol. Med. 112: 233, 1963

20. Sawitsky, A., Hyman, G. A. and Hyman, J. B.: An unidentified reticuloendothelial cell in bone marrow and spleen. Report of two cases with histochemical studies. Blood 9: 977-985, 1954

21. Samuels, S., Korey, S. R., Gonatas, J., Terry, R. D. and Weiss, M.: Studies in Tay-Sachs disease IV. Membranous cytoplasmic bodies. J. Neuropath. Exp. Neurol. 22: 81-97, 1963

22. Scharnbeck, H. and Schaffner, F.: Electron microscopic effects of digitonin in normal and cholestatic rat livers. Amer. J. Pathol. 61: 479-495, 1970

23. Schatta, H. S. and Neville, H. E.: Effects of cholesterol synthesis inhibitors on the nervous system. A light and electron microscopic study. Lab. Invest. 19: 487-493, 1968

24. Shikata, T., Oda, T., Naito, C., Kanetaka, T. and Suzuki, H.: Phospholipid fatty liver: A proposal of a new concept and electron microscopical study. Acta. Path. Jap. 20: 467-486, 1970

25. Shikata, T., Kanetaka, T., Endo, Y., Nishi, T., Kurumado, Y., Yoshiue, S. and Ishihara, Y.: Drug-induced phospholipid fatty liver cirrhosis., IGAKU NO AYUMI 80: 451-452, 1972 (Jap.)

26. Silverstein, M. N., Ellefson, R. D. and Ahern, E. J.: The syndrome of the seablue histiocyte. New Engl. J. Med. 282: 1-4, 1970

27. Silverstein, M. N. and Ellefson, R. D.: The syndrome of the sea-blue histiocyte., Seminars in hematology 9: 299-307, 1972

28. Stoecknius, W.: An electron microscopic study of myelin figures. J. Biophysic. and Biochem. 5: 491-515, 1959

29. Suga, Y., Kaneda, K., Furuzawa, Y.: A case report of the phagocytes showed a unique morphologic appearance in a bone marrow smear. J. Clinic. Hematology 6: 497-501, 1965 (Jap.) 
30. Tashiro, Y.: An electron microscopic observation on the cytological changes induced by 4,4'-diethylaminoethoxy hexestrol dihydrochloride. Jap. J. Clinic. Electron Microscopy 5: 77-78, 1972

31. Tashiro, Y., Enomoto, Y. and Watanabe, Y.: An electron microscopic observation on the cytological changes in experimental drug-induced lipidosis. 8th. International Congress on Electron Microscopy. Electron Microscopy, vol. II: 538-539, 1974.

32. Watanabe, Y., Watanabe, K., Tashiro, Y. and Enomoto, Y.: An electron microscopic observation on experimental phospholipidosis induced by 4,4'-diethylaminoethoxy hexestrol dihydrochloride in rat. J. Electron Microscopy 20: 255, 1971

33. Watanabe, Y. and Tashiro, Y.: An electron microscopic observation on the cellular changes by administration of 4,4'-diethylaminoethoxy hexestrol dihydrochloride. The 24th. Synposium for Cell Biology held at the Tsu. (1971)

34. Watanabe, Y. and Tashiro, Y.: The morphology of an experimental lipid storage disease induced by the administration of $\mathrm{DH}-4,4$ '-diethylaminoethoxy hexestrol dihydrochloride, J. Keio Med. Soc. 51: 151-164, 1974 (Jap.)

35. Williamson, J. R.: Ultrastructural localization and distribution of free cholesterol (3 $\beta$-hydroxysterols) in tissues. J. Ultrastructure Res. 27: 118-133, 1969

36. Yamamoto, A., Adachi, S., Ishikawa, K., Matsumura, T., Matsuzawa, Y. and Nishikawa, M.: The differences between animals in the processes of drug-induced lipidosis. IGAKU NO AYUMI 80: 75-76, 1972. (Jap.)

37. Yates, R. D., Arai, K. and Rappaport, D. A.: Fine structure and chemical composition of opaque cytoplasmic bodies of triparanol treated syrian hamsters., Exp. Cell Res. 47: 459-478, 1967

38. Novikoff, A. B.: Lysosomes and storage disease. Academic Press. 1973, p. 2-41

\section{EXPLANATION OF FIGURES}

Fig. 1-6 Various types of the myeloid bodies. The type I myeloid body with the whorls of membrane (Fig. 1). The type II myeloid body is the dense compact body with a regular periodicity of $45-55 \AA$ (Fig. 2). The type III myeloid body is the labyrinthine aggregates of closely packed membranes bounded by a distinct limiting membrane (Fig. 3) and without any limiting membrane showing a partially association with smooth-surfaced endoplasmic reticulum (Fig. $5)$. There are many intermediate types of various myeloid bodies showing a crystalline structure and lattice work; the intermediate myeloid bodies of type I-III (Fig. 6) and type I-IV (Fig. 4).

Fig. 7 A pericanalicular region (an early stage of formation of myeloid bodies, 3 days after the first administration of $\mathrm{DH}$ ). The Golgi vesicles and saccules seem to have increased and slightly dilated. A small number of precursors of the myeloid bodies is detected in the Golgi areas and shows a close association with the Golgi elements and smooth surfaced endoplasmic reticulum. (rat liver, $\times 24000$ ).

Fig. 8 With the continuation of $\mathrm{DH}$ administration, the internal whork-like structures become distinct in larger myeloid bodies and there are also those containing several whorls indicating that fusion of smaller bodies has occurred. 6 days' administration of DH. (rat liver, $\times 25000$ ).

Fig. 9 A portion of pericanalicular region. The number of myeloid bodies increased up to about 2 or 3 weeks, and then no appreciable increase in number of myeloid bodies was noticed. The majority of myeloid bodies in the early stage up to about 2 weeks was the type I and a small number of the type II bodies. 2 weeks' administration of DH. (rat river, $\times 6000$ ).

Fig. 10 Hepatocytes in the long term administration of DH. Numerous numbers of 
myeloid bodies are found. Various types of the myeloid bodies showing various internal structures and intermediate ories are detected. But in the lumen of the dilated bile canaliculi, the exocytosis of the myeloid bodies can never be found (100 days' administration, rat liver, $\times 10000)$.

Fig. 11 A high power view of the myeloid bodies in the long term administration of DH. The internal structures of the myeloid bodies are not monotonic and various types of the myeloid bodies and their intermediate ones are recognizable. (100 days' administration, rat liver, $\times 18000)$.

Fig. 12 A portion of intrahepatic bile duct. Numerous numbers of the type I myeloid bodies and their complexed ones occupy the whole cytoplasms of epithelial cells of bile ducts. In the lumen of the bile duct, the myeloid bodies are released by cellular collapse (arrow). (100 days' administration of DH, rat liver, $\times 7500$ ).

Fig. 13 A portion of hepatocytes, 3 weeks after the termination of DH administration for 2 weeks. Myeloid bodies begin to decrease in number and their electron density increases more and more. At the same time, their internal structures, such as whorls of membranes, reticular pattern and lattice pattern and lattice pattern become obscure. (rat liver, $\times 12000$ ).

Fig. 14 A small portion of the hepatocytes, 7 weeks after the termination of $\mathrm{DH}$ administration for two weeks. The myeloid bodies showing various internal structures almost disappear and in place of them, a few peribiliary dense bodies and autophagic vacuoles are detected. (rat liver, $\times 13000$ ).

Fig. 15 Light micrograph of histochemistry of rat liver. The reaction products for acid phosphatase increased markedly as compared with control groups. (60 days' administration, rat liver, $\times 800$ ).

Fig. 16 Electron micrograph of cytochemistry. Reaction products for acid phosphatase are detected in the matrix and the central core of the myeloid bodies. (rat liver, $\times 32000$ ).

Fig. 17 Digitonin-cholesterol complexes are found in the matrix of the myeloid bodies and recognized as darkly stained needles or spicules. On cross section, they presented as dark circles or spiral-like lamellar structures. Spirals consisted of $1 \frac{1 / 2}{2}$ turns. ( 60 days' administration, rat liver, $\times 47000$ ).

Fig. 18 The same spiral like lamellar structures of digitonin-cholesterol complexes. are also found in the matrix of type III myeloid body. (60 days' administration, rat river, $\times 52000$ ).

Fig. 19 An early stage of formation of myeloid bodies at the portion of supranuclear region in the rat pancreas. A small number of dense myeloid bodies and their precursors are found near the Golgi areas. (2 days' administration of DH, rat pancreas, $\times 22000$ ).

Fig. 20 The myeloid bodies increase in number gradually. Throughout the course of of $\mathrm{DH}$ administration, the type II and their complexed ones predominated in the pancreatic acinar cells. (3 days' administration of $\mathrm{DH}$, rat pancreas, $\times 11000$ ).

Fig. 21 The myeloid bodies increase in number and become soon more complex and larger in proportion to the periods of administration. Some of the largest complexed myeloid bodies reach the size of nucleus or more. (60 days' administration of $\mathrm{DH}$, rat pancreas, $\times 4000$ ).

Fig. 22 An apical portion of the pancreatic acinar cell. Discharge of the contents of the myeloid bodies which has reached the apical portion of the cell into the extracellular space occurs presumably by exocytosis as for zymogenic secretory granules. (100 days' administration of DH, rat pancreas, $\times 23000$ ).

Fig. 23 An apical portion of the epithelial cell of pancreatic duct showing the exocytotic figure same as shown in the Fig. 22. (100 days' administration of DH, 
rat pancreas, $\times 28000)$.

Fig. 24 The purified myeloid bodies isolated from rat river of 100 days' administration of DH. $(\times 8000)$. 


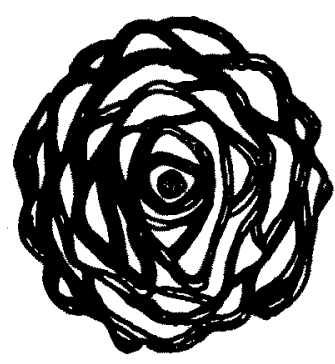

TYPE I

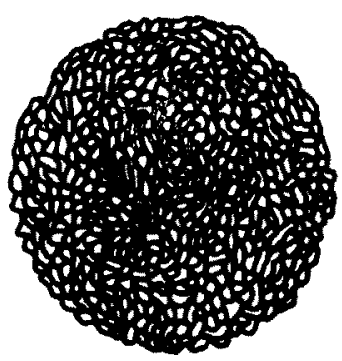

TYPE III

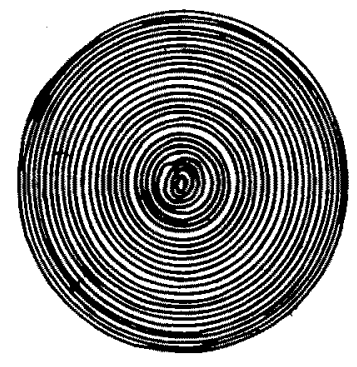

TYPE II

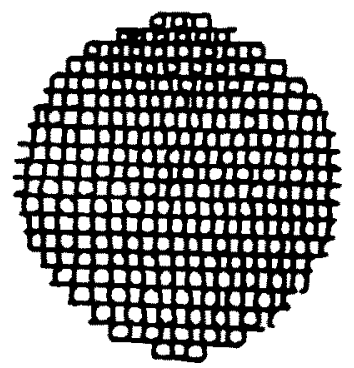

TYPE IV

Schema 1

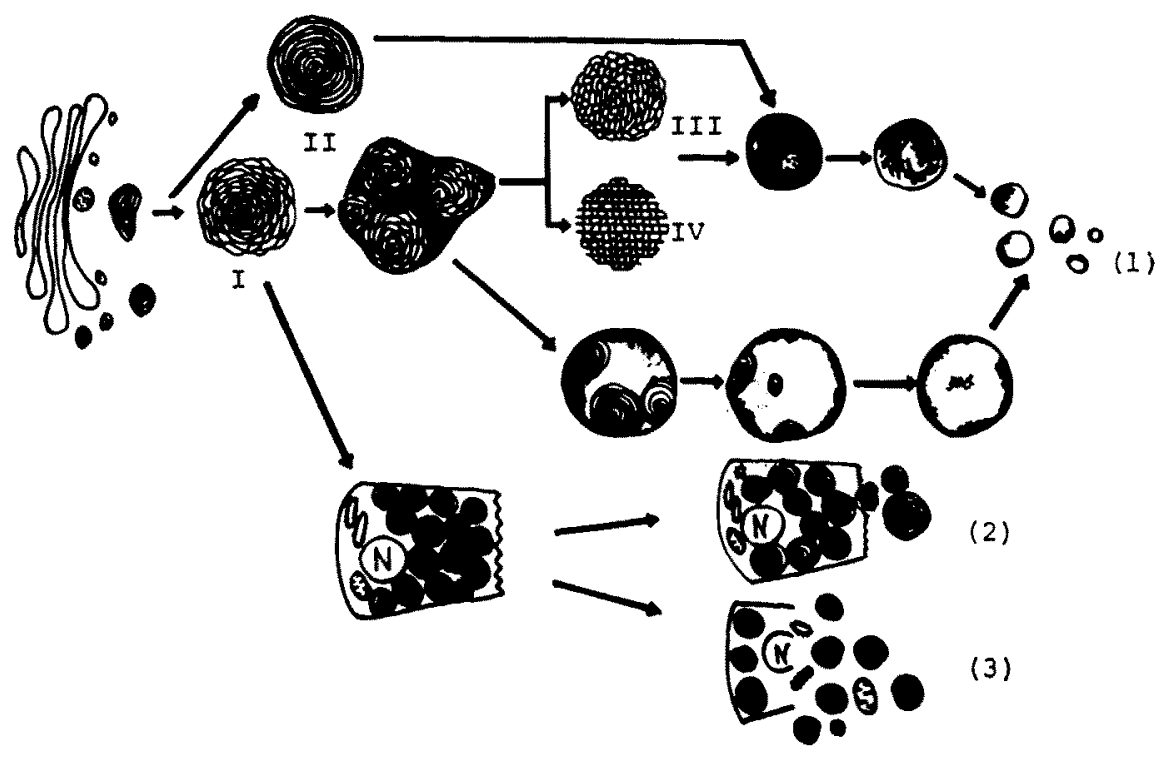

Schema 2 


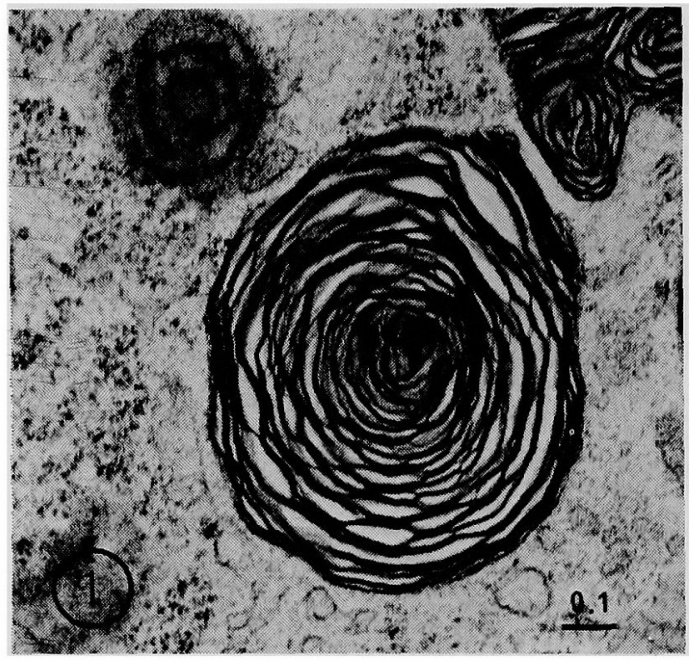

Fig. $1 \times 55000$

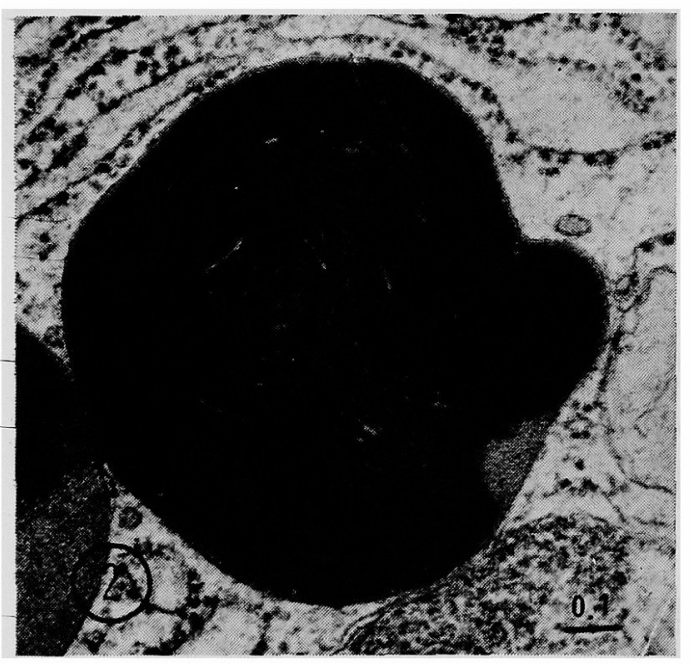

Fig. $2 \times 53000$

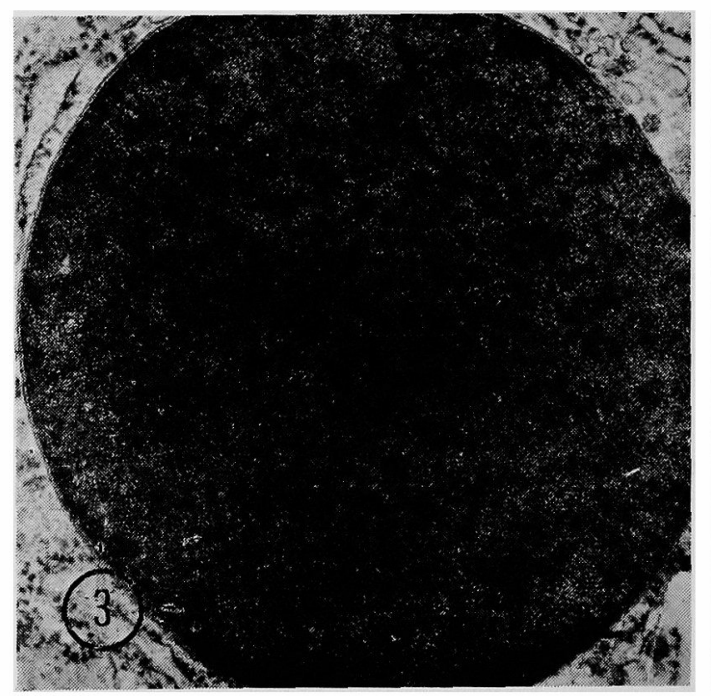

Fig. $3 \times \mathbf{4 4 0 0 0}$

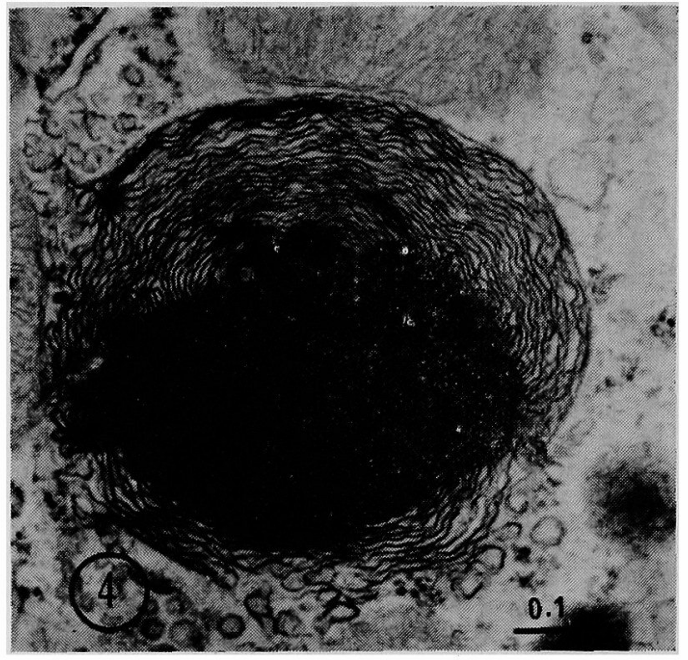

Fig. $4 \times 63000$

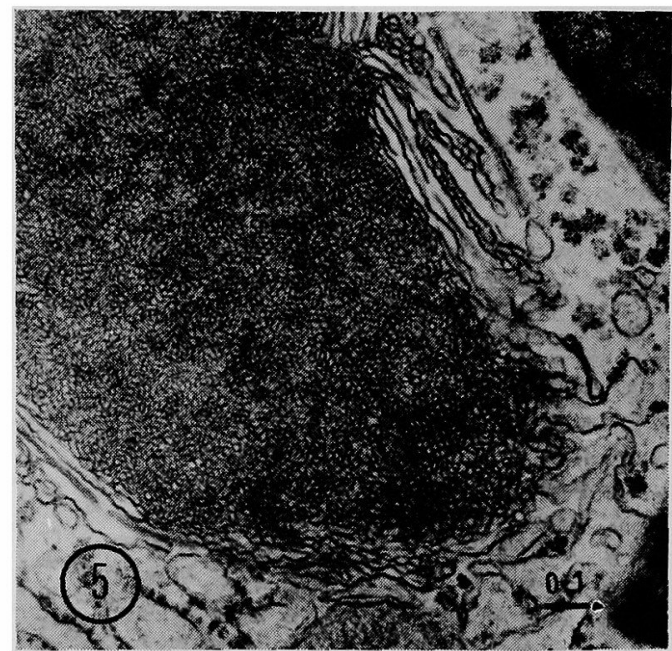

Fig. $5 \times 47000$

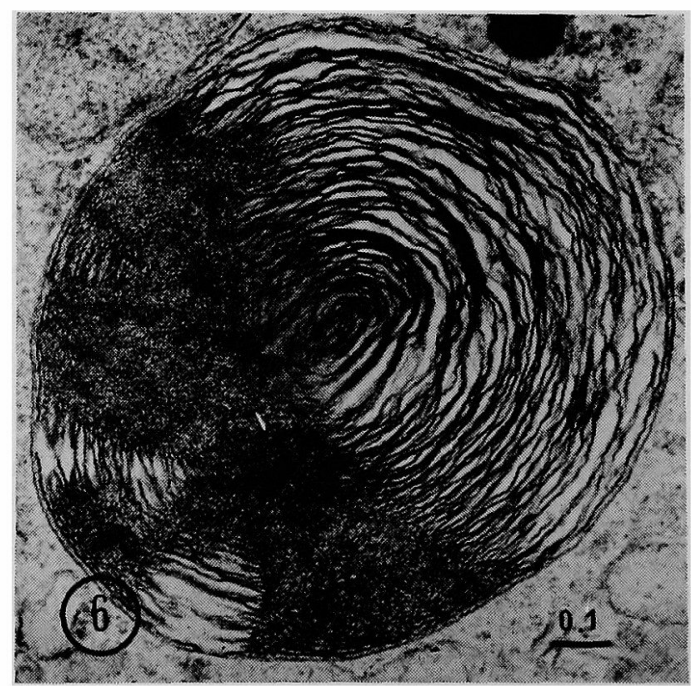

Fig. $6 \times 57000$ 


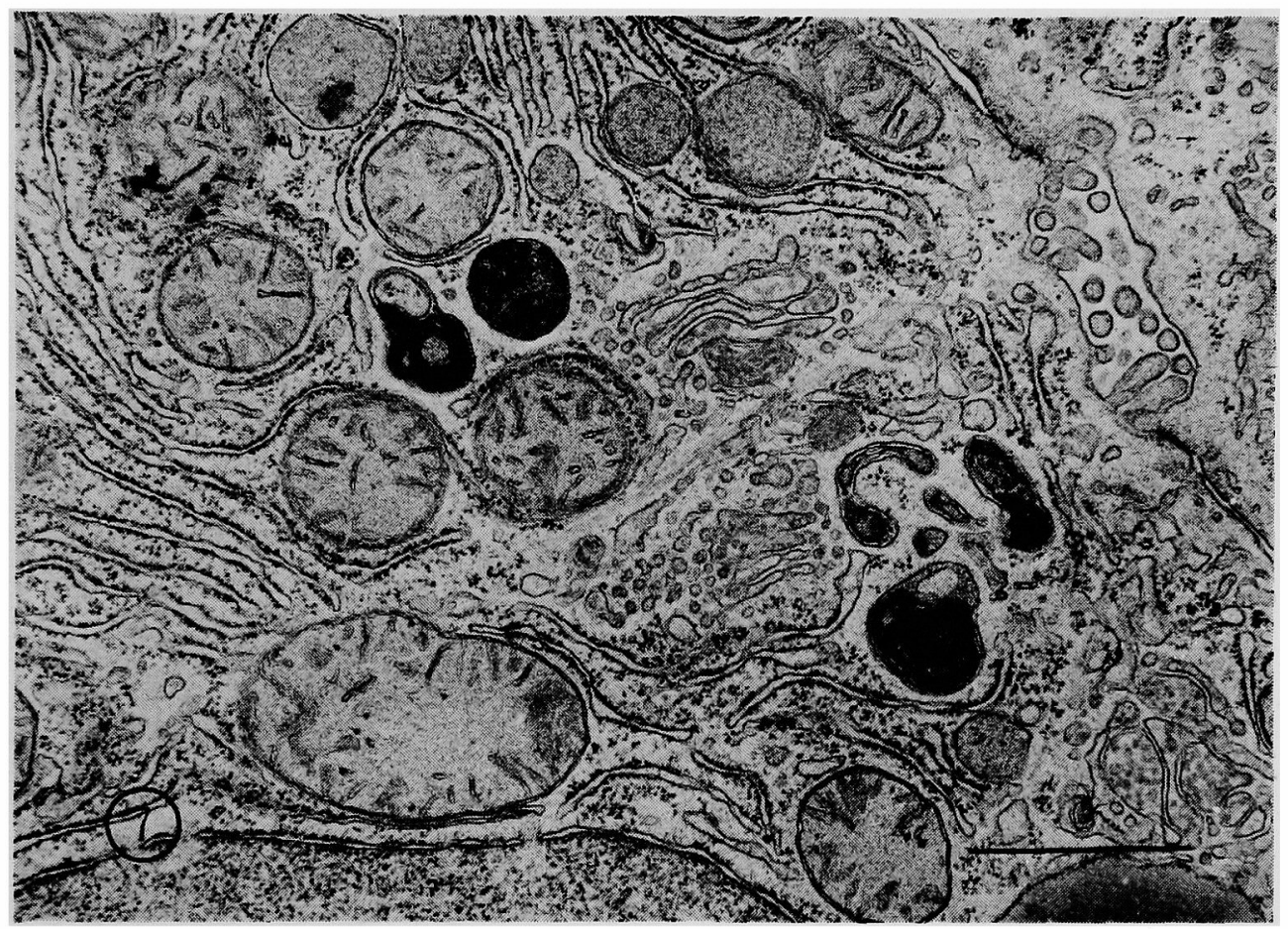

Fig. $7 \times 24000$

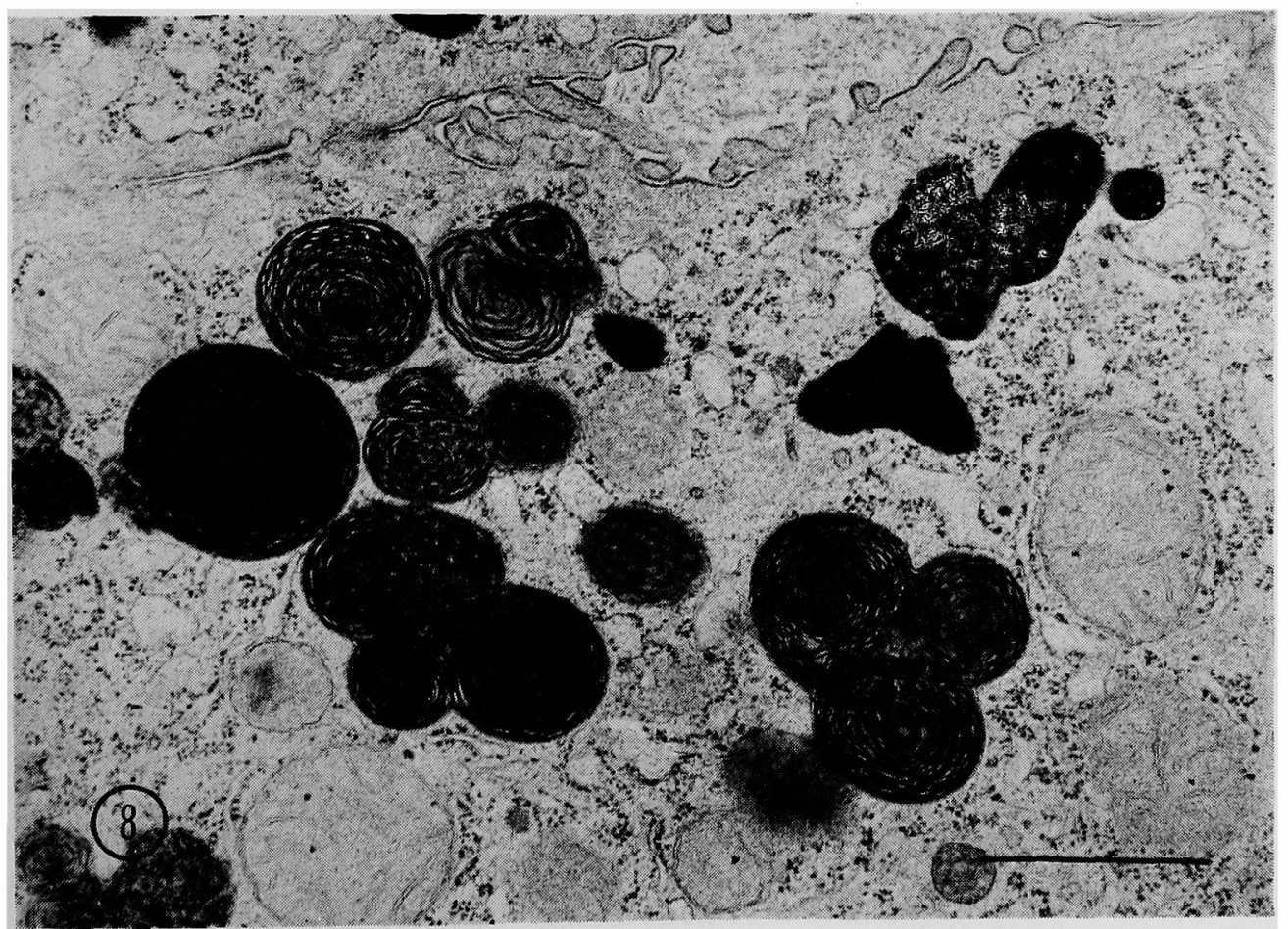

Fig. $8 \times 25000$ 


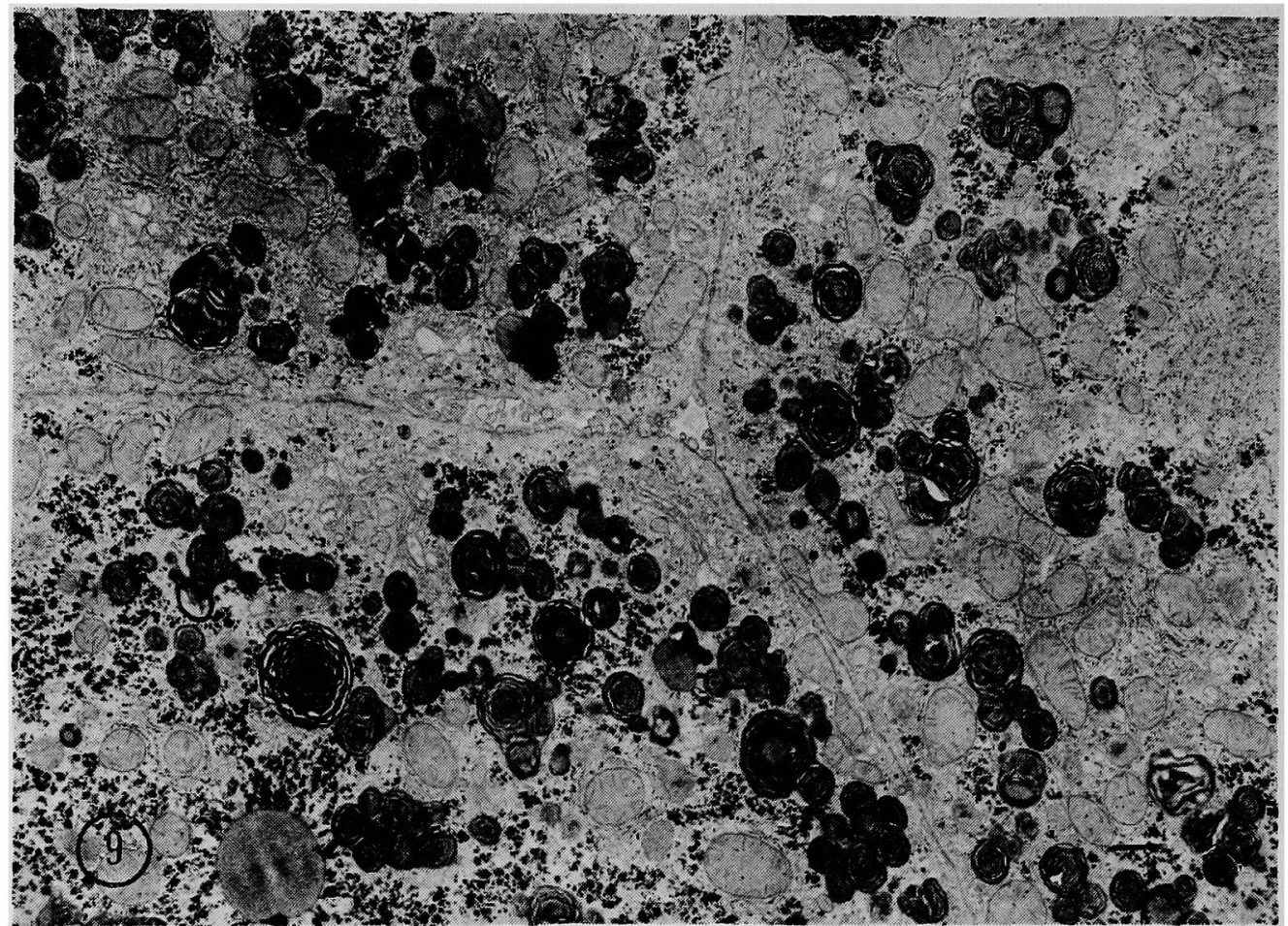

Fig. $9 \times 6000$

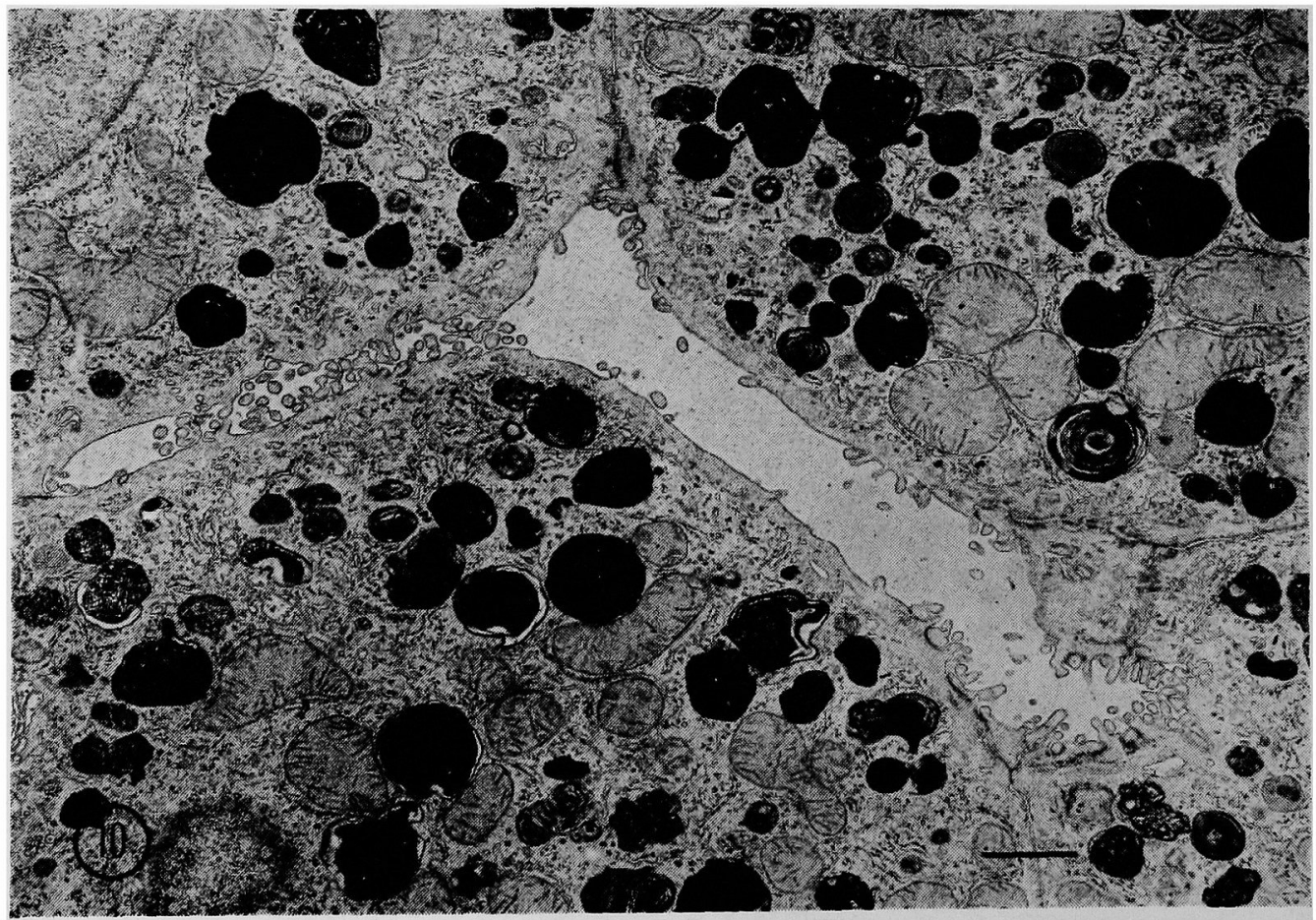

Fig. $10 \times 10000$ 


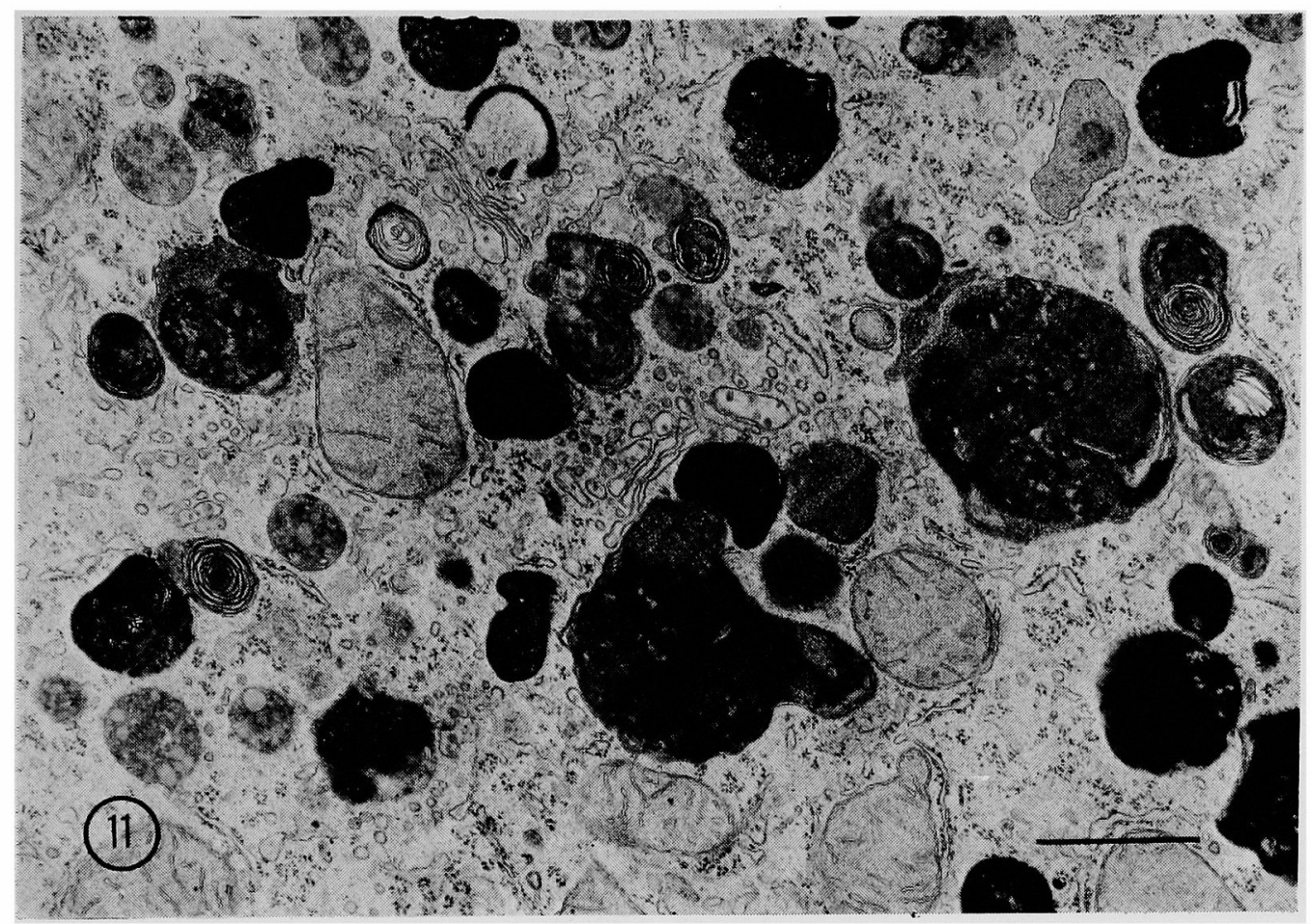

Fig. $11 \times 18000$

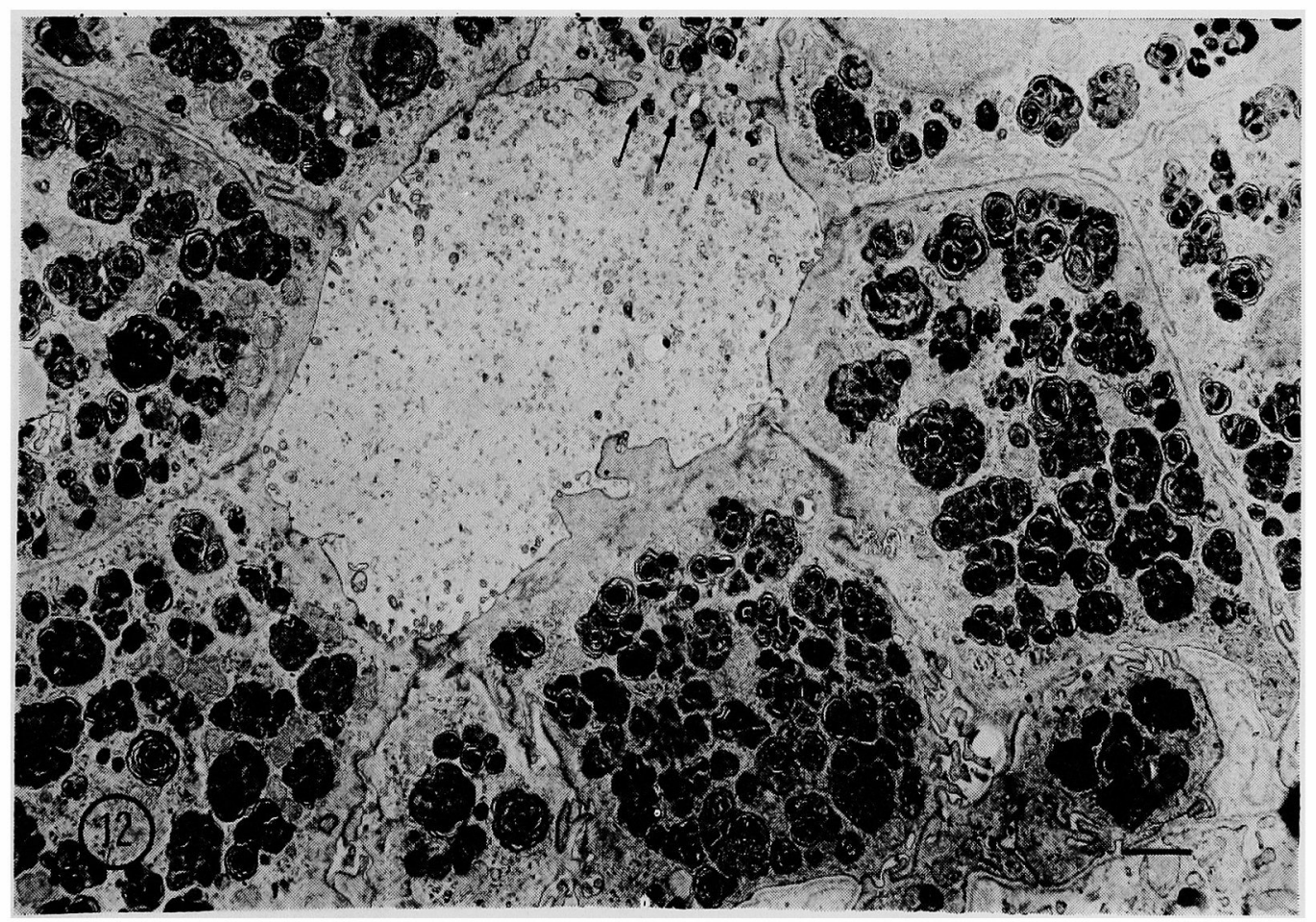

Fig. $12 \times 7000$ 


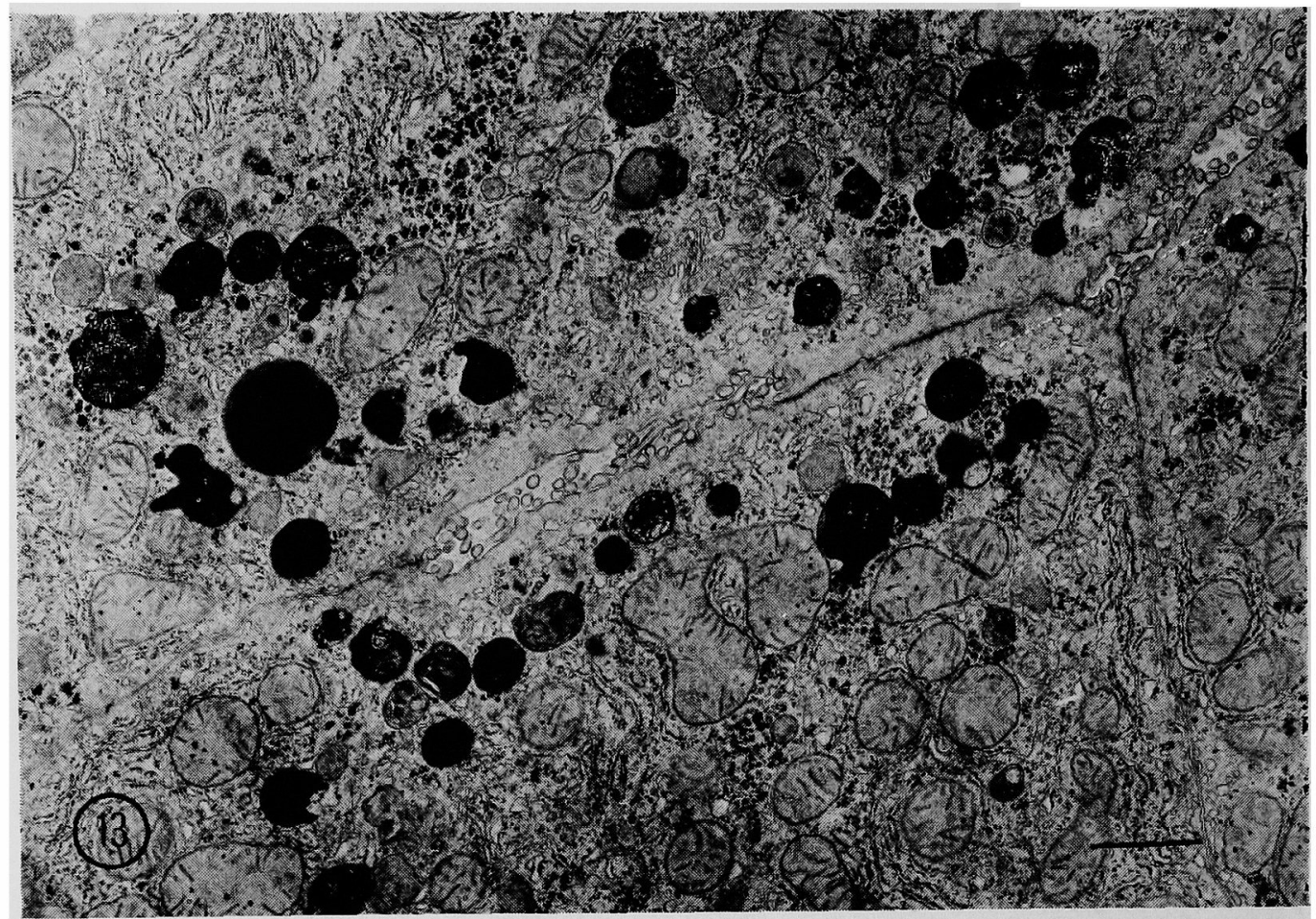

Fig. $13 \times 12000$

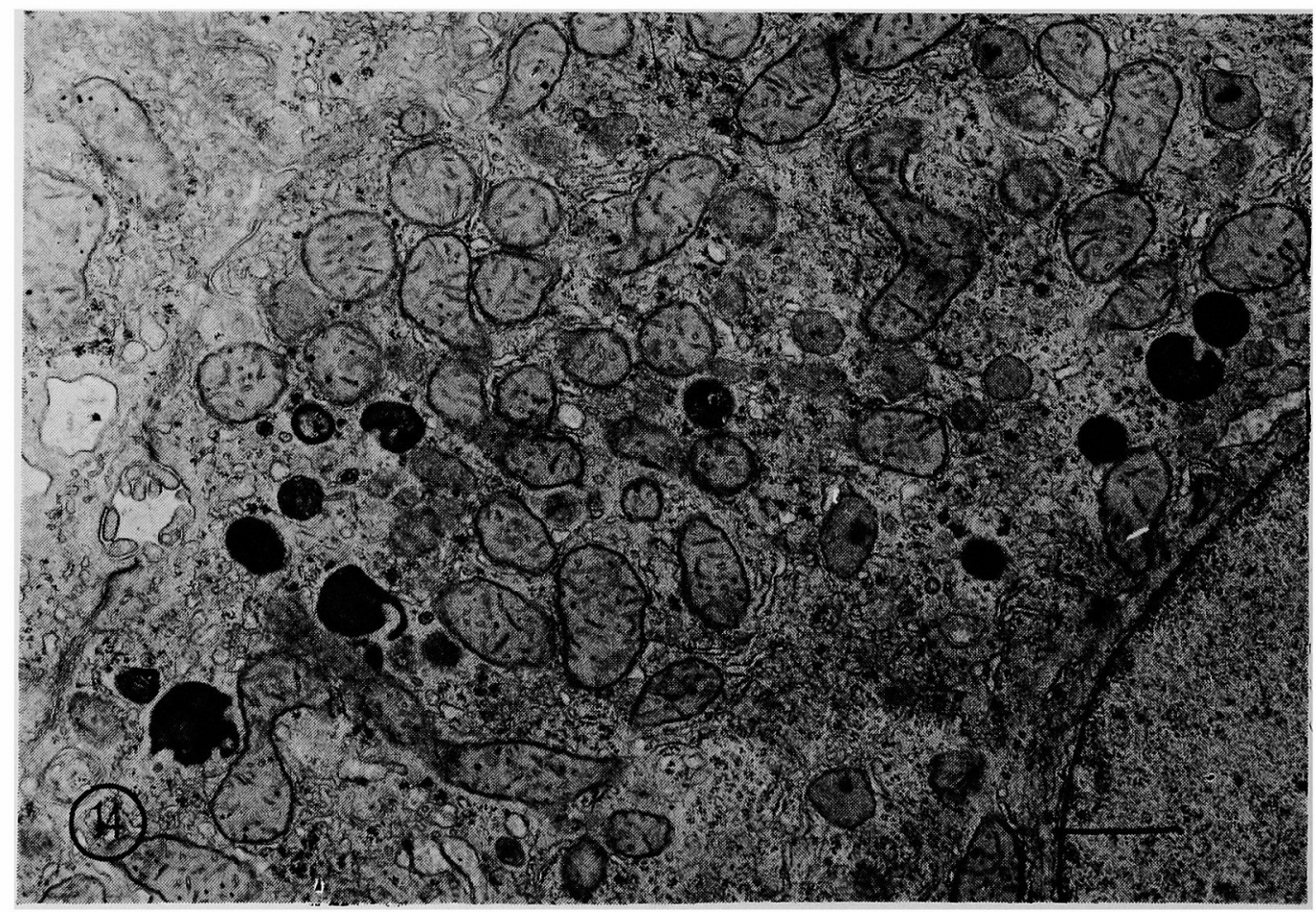

Fig. $14 \times 13000$ 


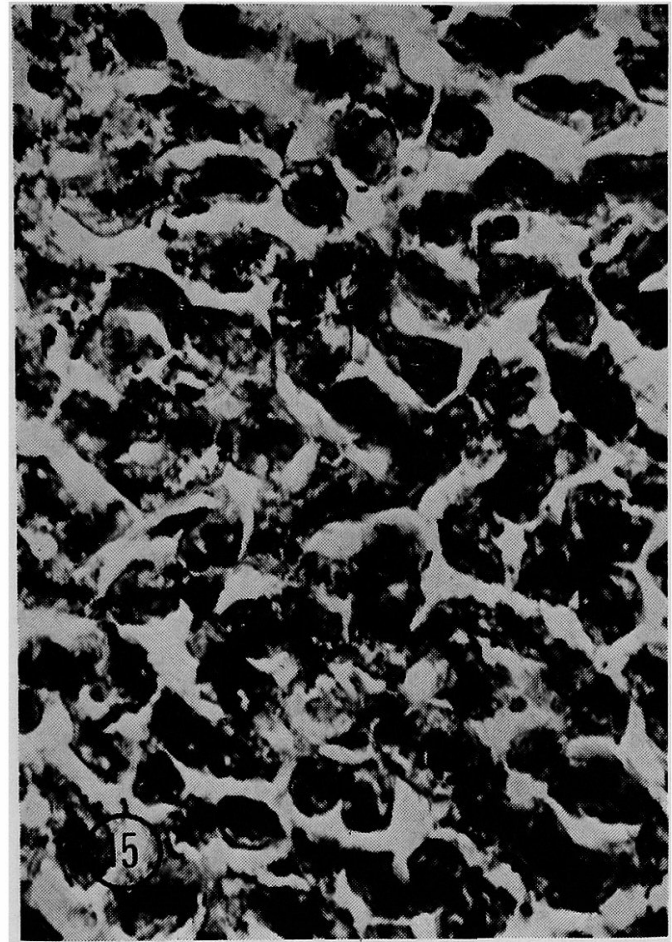

Fig. $15 \times 800$

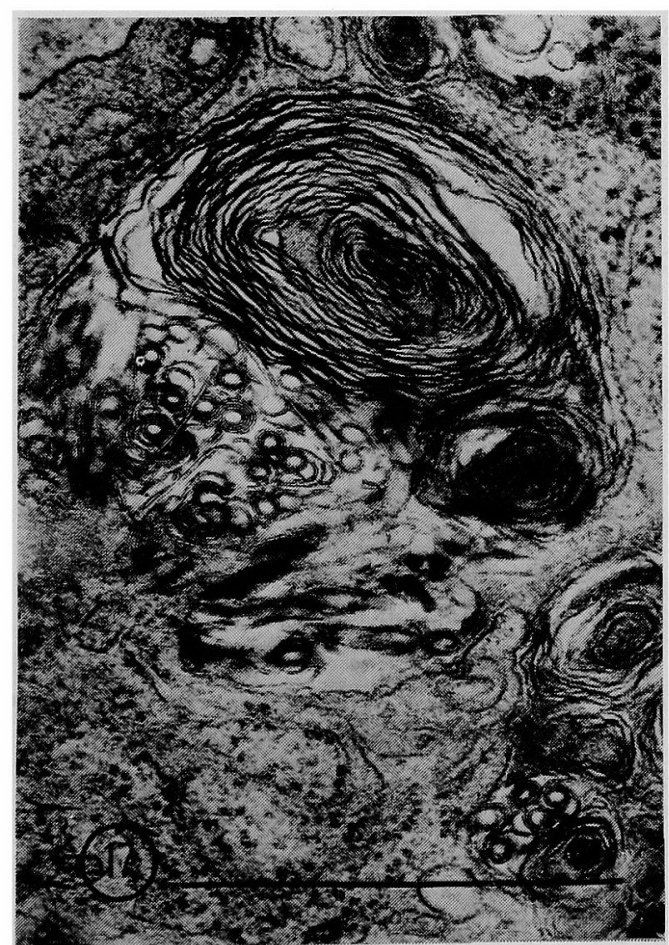

Fig. $17 \times 47000$

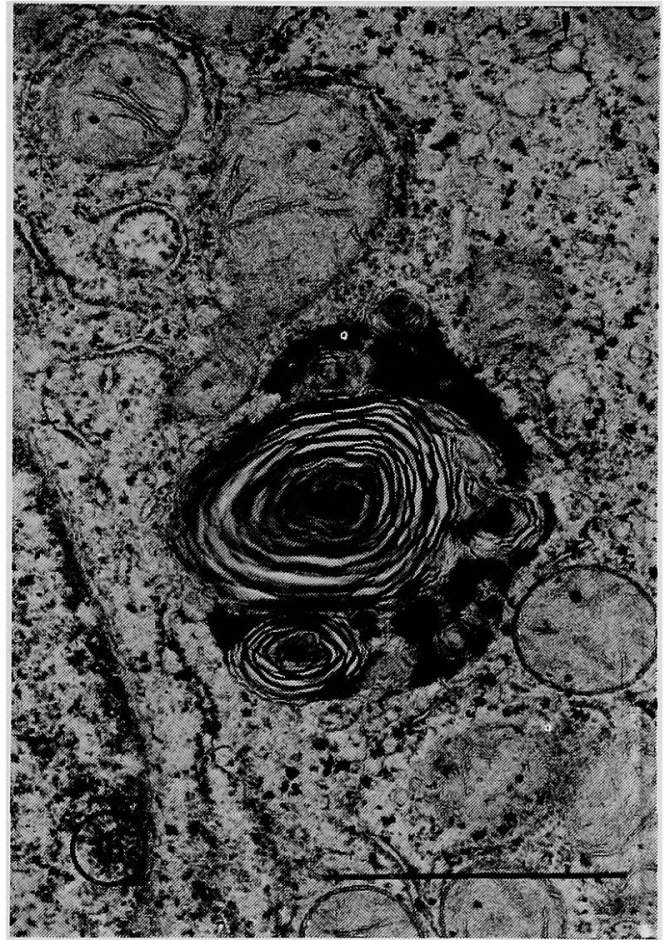

Fig. $16 \times 32000$

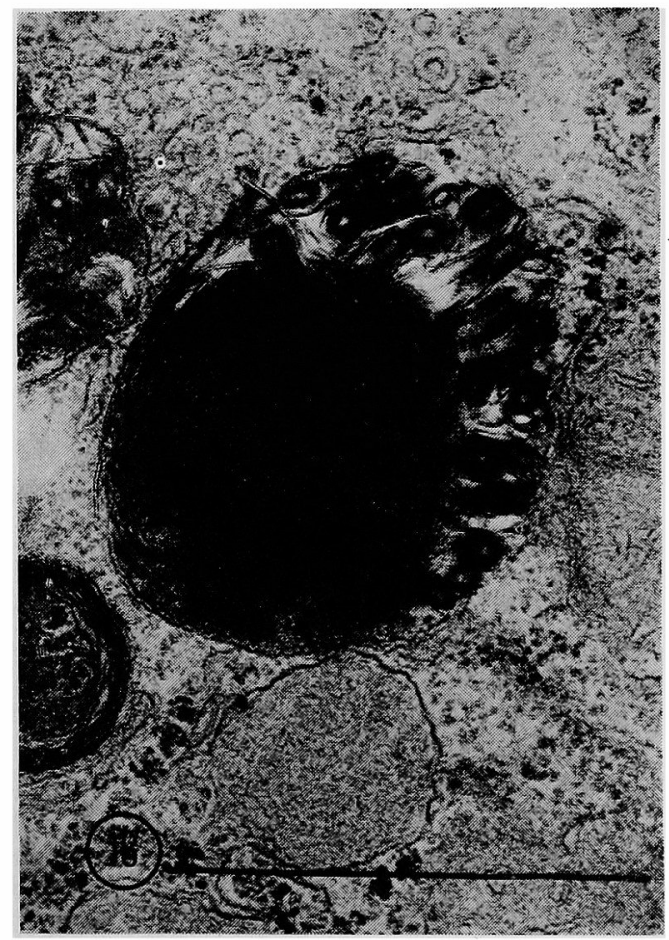

Fig. $18 \times 52000$ 


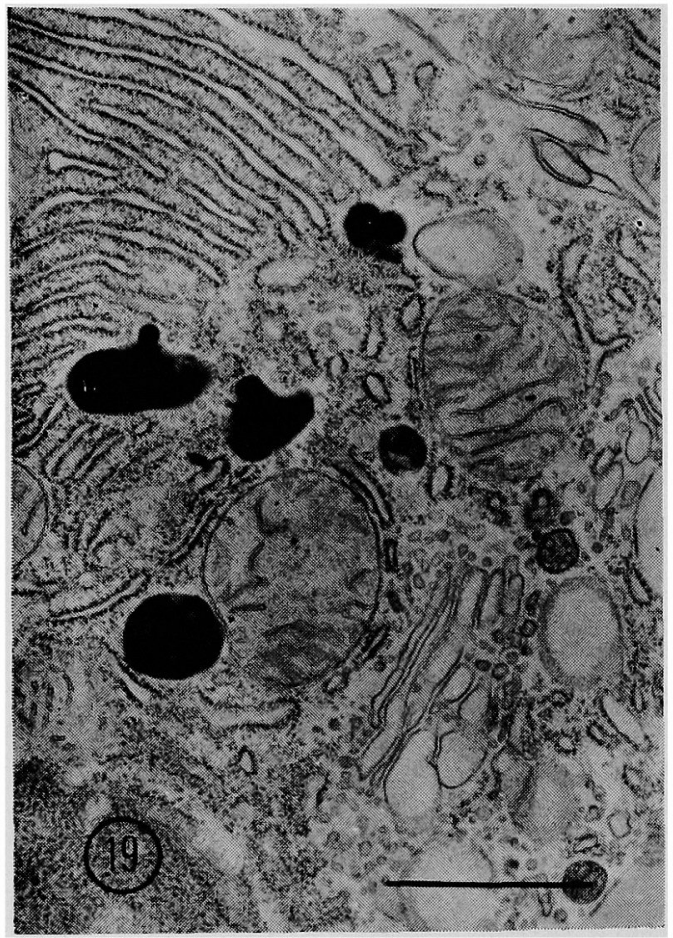

Fig. $19 \times 22000$

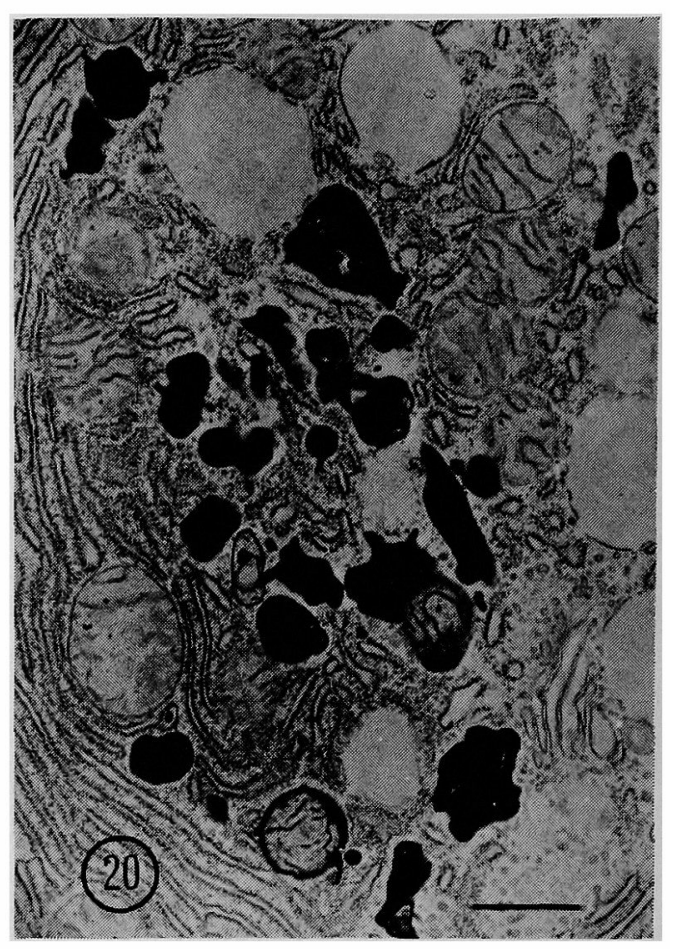

Fig. $20 \times 11000$

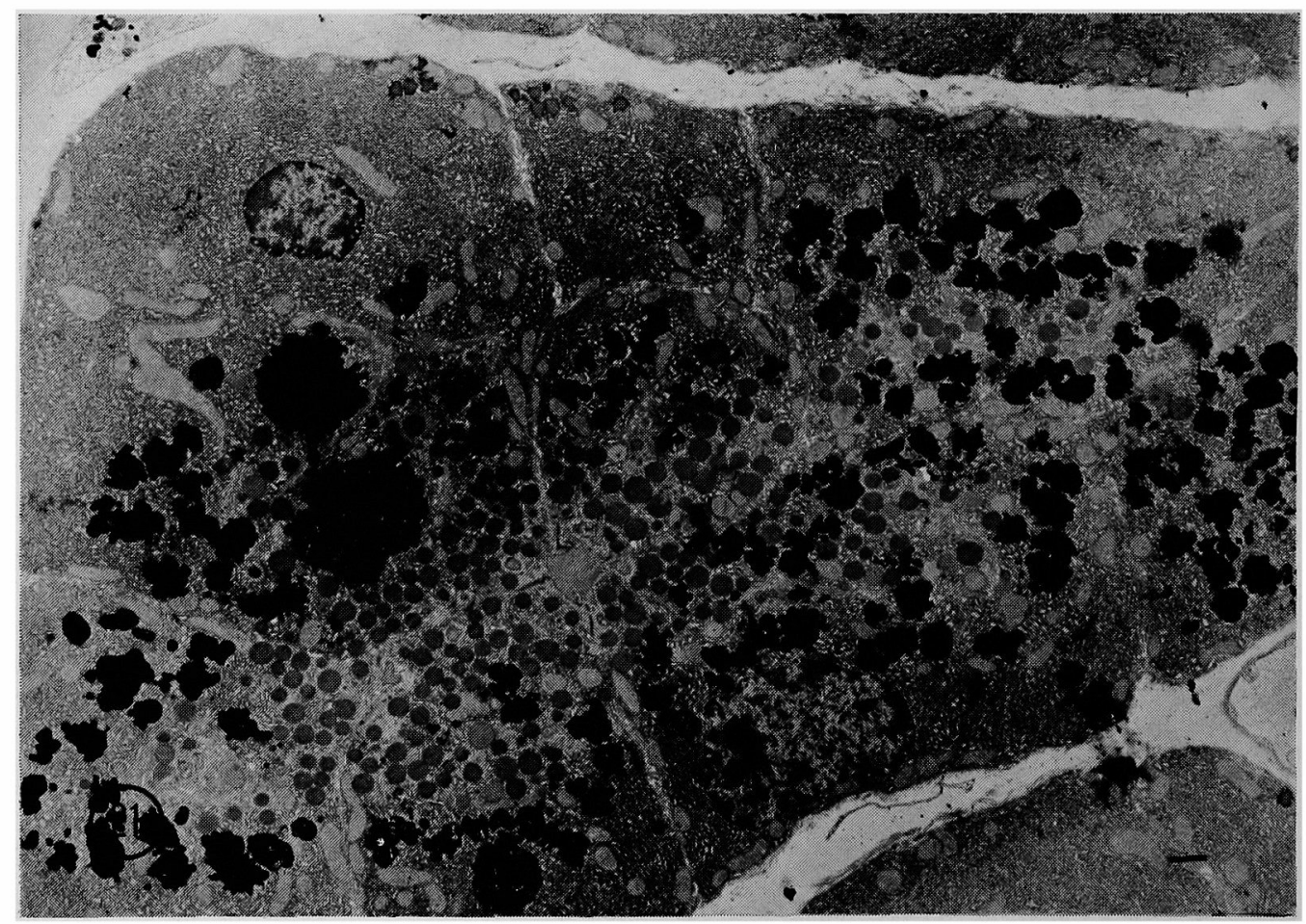

Fig. $21 \times 4000$ 


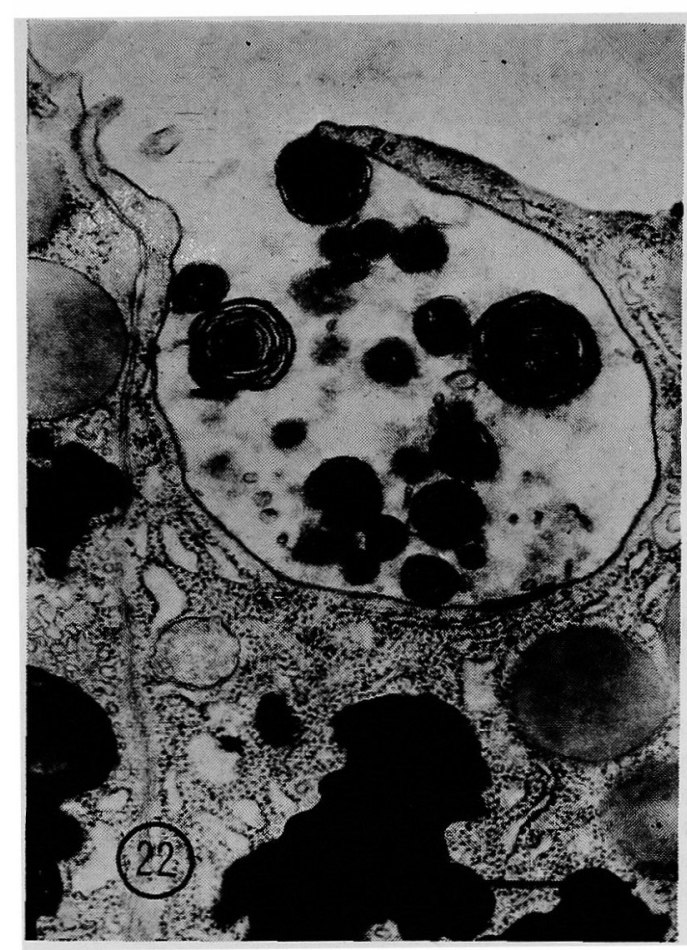

Fig. $22 \times 23000$

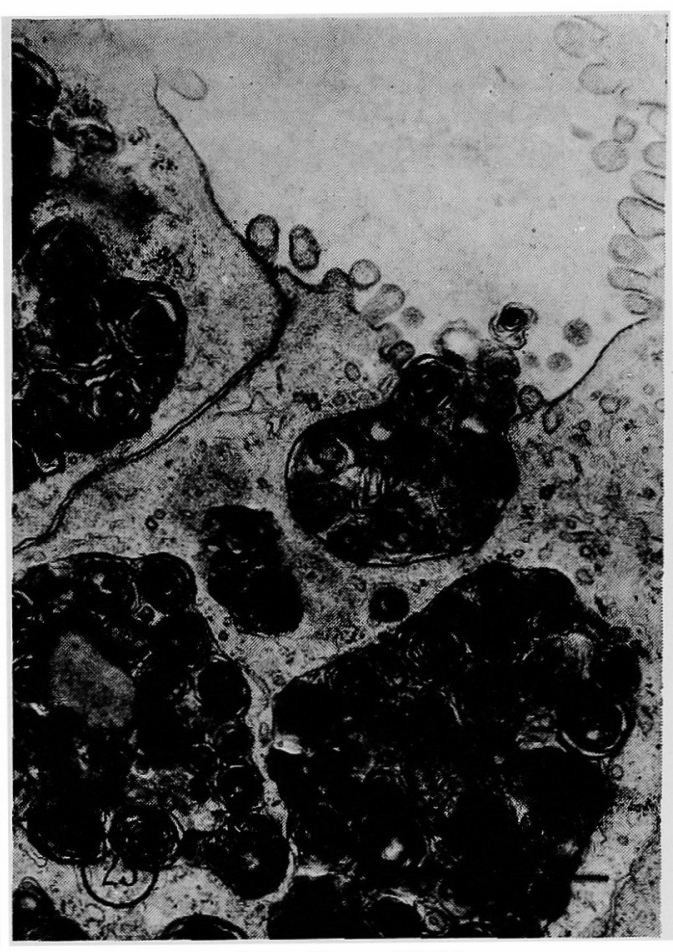

Fig. $23 \times 28000$

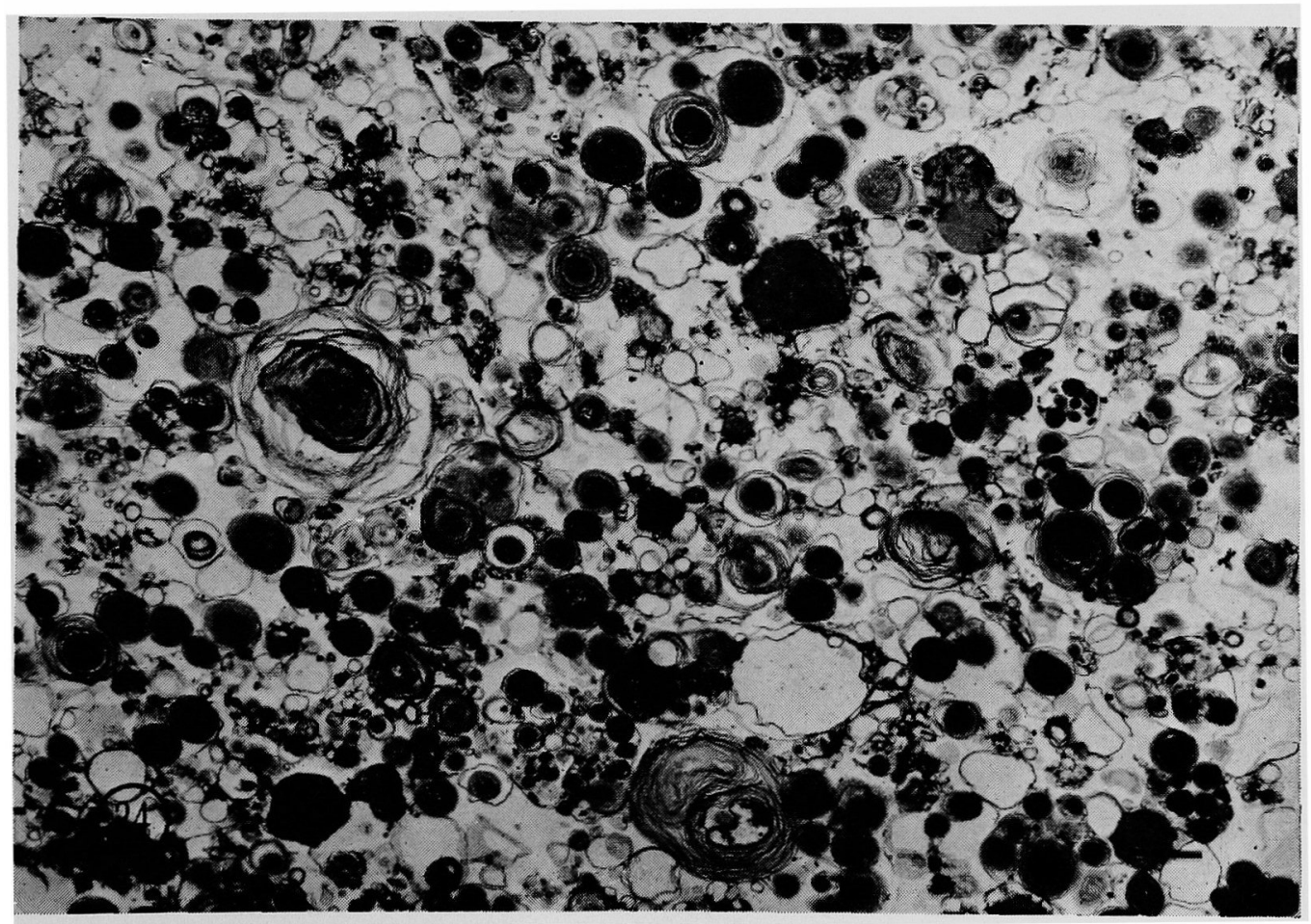

Fig. $24 \times 8000$ 